\title{
Effectiveness and safety of tapentadol prolonged release with tapentadol immediate release on-demand for the management of severe, chronic osteoarthritis-related knee pain: results of an open-label, phase $3 \mathrm{~b}$ study
}

\author{
This article was published in the following Dove Press journal: \\ Journal of Pain Research \\ 14 June 2012 \\ Number of times this article has been viewed
}

\author{
Ilona Steigerwald' \\ Matthias Müller' \\ Jolanta Kujawa ${ }^{2}$ \\ Jean-Charles Balblanc ${ }^{3}$ \\ Jaime Calvo-Alén ${ }^{4}$ \\ 'Medical Affairs Europe \& Australia, \\ Grünenthal GmbH, Aachen, Germany; \\ ${ }^{2}$ Medical University of Lodz, Medical \\ Rehabilitation Clinic, Lodz, Poland; \\ ${ }^{3}$ Department of Rheumatology, \\ General Hospital of Belfort, Belfort, \\ France; ${ }^{4}$ Hospital Universitario \\ Sierrallana and IFIMAV Research \\ Institute, Universidad de Cantabria, \\ Cantabria, Spain
}

\begin{abstract}
This open-label, phase 3b study (ClinicalTrials.gov Identifier: NCT00983073) evaluated the effectiveness, and tolerability of tapentadol for severe, chronic osteoarthritis knee pain that was inadequately managed with World Health Organization (WHO) Step I or II analgesics or co-analgesics, or that was not treated with regular analgesics. Prior to starting study treatment, patients discontinued any WHO Step II analgesics, while Step I analgesics and/or co-analgesics were continued at the same dose. Patients received tapentadol prolonged release (50-250 mg bid) during a 5-week titration period and a 7-week maintenance period. Doses of tapentadol immediate release $50 \mathrm{mg}$ ( $\leq$ twice/day; $\geq 4$ hours apart) were permitted throughout the study (total daily dose of tapentadol prolonged and immediate release, $\leq 250 \mathrm{mg}$ bid). The primary endpoint was the change in pain intensity on an 11-point numerical rating scale-3 (NRS-3; recalled average pain intensity [11-point NRS] during the last 3 days) from baseline to Week 6, using the last observation carried forward (LOCF) to impute missing pain intensity scores. The mean (standard deviation) change from baseline to Week 6 (LOCF) in pain intensity was $-3.4(2.10 ; P<0.0001)$ for all patients evaluated for effectiveness $(\mathrm{n}=195)$. Significant decreases in pain intensity were also observed at Weeks 6, 8, and 12 (all $P<0.0001$ ) using observed-case analysis. Corresponding significant improvements from baseline to Weeks 6 and 12 were observed in the Western Ontario and McMaster Universities osteoarthritis index, the EuroQol-5 Dimension health status questionnaire, the Short Form-36 health survey, and the Hospital Anxiety and Depression Scale (all $P \leq 0.0103$ ). Treatment-emergent adverse events were in line with those observed in previous studies of tapentadol prolonged release. Overall, the results of this study indicate that tapentadol treatment results in significant improvements in pain intensity, health-related quality of life, and function in patients with inadequately managed, severe, chronic osteoarthritis knee pain.
\end{abstract}

Keywords: tapentadol, osteoarthritis, chronic pain, opioid

\section{Introduction}

Osteoarthritis is the most common form of arthritis ${ }^{1,2}$; the prevalence of osteoarthritis ranges from $10.8 \%$ to $14.7 \%$ in the general adult population in developed countries and increases with increasing age. ${ }^{2}$ In a study of approximately 4 million patients who visited health care professionals or hospitals in British Columbia in 2001 , the estimated prevalence of osteoarthritis increased from $6.9 \%$ for patients
Correspondence: Ilona Steigerwald Grünenthal GmbH, Zieglerstrasse 6, 52078 Aachen, Germany

Tel +4924I 5692392

Fax +49 24I 56952392

Email ilona.steigerwald@grunenthal.com 
40 to 44 years of age to $26.4 \%$ for patients 60 to 64 years of age and $49.0 \%$ for patients 80 to 84 years of age. ${ }^{3}$ Symptomatic osteoarthritis most commonly affects the knees, hips, hands, or feet. ${ }^{4}$ Osteoarthritis pain can have a significant negative impact on health-related quality of life and may be associated with an increased risk of anxiety or depression. ${ }^{5,6}$ In addition, osteoarthritis-related knee and hip pain are the primary causes of reduced mobility among the elderly. ${ }^{7}$

Opioid analgesics have been shown to relieve osteoarthritis pain $^{8-10}$ and to improve health-related quality of life and physical function. ${ }^{11}$ Opioid treatment may not be effective for all patients with osteoarthritis pain because of variations in patient response to pure $\mu$-opioid agonist treatment, ${ }^{12}$ which may be caused by multiple factors, including different degrees of central sensitization. ${ }^{13,14}$ In addition, there is evidence that descending inhibitory pain pathways are disrupted in chronic musculoskeletal pain conditions, and pharmacotherapies that target descending pain pathways (eg, those that block serotonin or norepinephrine reuptake) may be more appropriate for managing chronic pain than pure $\mu$-opioid receptor agonists. ${ }^{13,15,16}$ Drugs possessing both norepinephrine reuptake inhibition and serotonin reuptake inhibition abilities may have a less clear analgesic profile because the serotonergic component of their mechanism of action can enhance descending pain inhibition (resulting in an analgesic effect) or facilitate pain signaling (resulting in a pro-algesic effect). ${ }^{17,18}$ Variations in patient response to opioid analgesia and the contribution of dysfunction of descending inhibitory pain pathways may leave some patients treated with pure $\mu$-opioid receptor agonists or co-analgesics with undermanaged osteoarthritis pain and corresponding poor health status and quality of life. ${ }^{12,13}$ In addition, opioid analgesics are often associated with side effects, particularly gastrointestinal side effects, that may limit patients' longterm compliance with treatment. ${ }^{19-21}$

Tapentadol is a centrally acting analgesic that acts through $\mu$-opioid receptor agonism and noradrenaline reuptake inhibition. ${ }^{22,23}$ The efficacy and safety of tapentadol prolonged release (100-250 mg bid) for the management of moderate to severe, chronic osteoarthritis pain has been assessed. ${ }^{2-26}$ The current open-label phase $3 \mathrm{~b}$ study (ClinicalTrials.gov Identifier: NCT00983073) evaluated the effectiveness and tolerability of tapentadol in patients with severe, chronic osteoarthritis knee pain that was inadequately managed with World Health Organization (WHO) Step I or II analgesics or co-analgesics or that was not treated with regular analgesics.

\section{Patients and methods}

\section{Patient population}

Patients were selected for this study based on the following inclusion criteria:

- At least 40 years of age

- A diagnosis of osteoarthritis of the knee based on the American College of Rheumatology classification criteria (knee pain and radiographic osteophytes or at least 40 years of age with knee pain, morning stiffness of at least 30 minutes duration, and crepitus on motion); patients with osteoarthritis at joints other than the reference knee joint were allowed to participate in the study if the reference joint was the main source of pain and disability

- Pain at the reference joint for a minimum of 3 months prior to screening

- WHO Step I or II analgesic treatment for osteoarthritisrelated knee pain for a minimum of 2 weeks before screening (for patients taking regular daily pretreatment)

- Pain requiring a strong (WHO Step III) analgesic that could not be adequately managed with an increase in the dose of WHO Step I analgesics (as monotherapy or combination therapy) or continuation with or an increase in the dose of WHO Step II analgesics (based on the investigator's assessment)

- Average pain intensity score at screening of at least 5 on an 11-point numerical rating scale-3 (NRS-3; recalled average pain intensity [11-point NRS] during the 3 days before a study visit; $0=$ "no pain" to $10=$ "pain as bad as you can imagine") for patients taking regular pretreatment with WHO Step I or II analgesics

- Average pain intensity score at screening of at least 6 (11-point NRS-3) for patients taking no regular daily pretreatment

- Ratings of satisfaction with prior analgesic treatment (either WHO Step I or II analgesics or no regular pretreatment) of not better than "fair" on a 5-point verbal rating scale (VRS; 0 = "poor", 1 = "fair", 2 = "good", 3 = "very good", 4 = "excellent")

Patients were excluded from the study based on the following criteria:

- Pregnancy or lactation

- Known or suspected inability to comply with the protocol and use of study medication

- Participation in another study concurrently or within 4 weeks prior to screening

- Any painful procedure (eg, major surgery or surgery at the reference joint) required during the study that could impact effectiveness and safety assessments 
- Clinically significant disease, laboratory findings, active systemic or local infection, conditions other than osteoarthritis at the reference joint, significant skin conditions (eg, abscess), widespread pain syndromes (eg, fibromyalgia), or other concomitant painful conditions that could interfere with pain intensity, quality of life, function, or safety assessments

- Osteoarthritis in a flare state or a history and clinical signs of crystal-induced (eg, gout or pseudogout), metabolic, infectious, or autoimmune disease at the reference joint

- Concomitant autoimmune inflammatory conditions

- A history of human immunodeficiency virus infection

- A history of alcohol or drug abuse

- A history of, or laboratory values reflecting, severe renal impairment or a history of moderate or severe hepatic impairment

- A history of active hepatitis B or C within the 3 months prior to screening

- A history of brain neoplasm, transient ischemic attack, stroke, or mild or moderate traumatic brain injury within the year prior to screening or residual sequelae indicative of transient changes in consciousness or a history of severe traumatic brain injury within 15 years prior to screening

- Contraindications to tapentadol (eg, known or suspected paralytic ileus or acute or severe bronchial asthma or hypercapnia) or a history of allergy or hypersensitivity to tapentadol or its excipients

The following drugs were prohibited during the study and within the specified timeframes prior to screening: monoamine oxidase inhibitors within 14 days of screening, unstably dosed selective serotonin reuptake inhibitors within 30 days of screening, WHO Step III analgesics within 30 days of screening, and intra-articular injections of hyaluronic acid in the reference joint within 3 months of screening. Patients were permitted to take serotonin reuptake inhibitors if their doses remained stable throughout the study.

\section{Study design}

This phase $3 \mathrm{~b}$ study had an open-label, multicenter design with a 12-week treatment period with tapentadol, including a 5-week titration period and a 7-week maintenance period. The titration period was immediately preceded by a 1 -week observation period under the previous analgesic treatment regimen (Week -1 ) that started with the screening visit and ended with the baseline visit; during the titration period, all analgesics, co-analgesics, and drugs for the treatment of opioid-induced side effects were recorded by the patients in a daily diary. Patients continued taking their pre-study regimens of all WHO Step I analgesics, co-analgesics, and drugs for the treatment of opioid-induced side effects with no further dose adjustments during the titration period and the remainder of the study (unless they were participating in a tapering substudy as described below). Doses of non-steroidal anti-inflammatory drugs (NSAIDs) could be increased for documented inflammatory flares of osteoarthritis and laxatives could be discontinued if laxative-induced diarrhea occurred after patients switched to tapentadol prolonged release. Patients taking WHO Step II analgesics discontinued these analgesics at the end of the observation period (on the evening of the day of the baseline visit).

On the morning after the baseline visit, eligible patients initiated study treatment with tapentadol prolonged release $50 \mathrm{mg}$ bid. Three days after the start of study medication, an initial titration was permitted if necessary. Doses of tapentadol prolonged release were then titrated each week as needed (within the therapeutic dose range of 50-250 mg bid) until patients achieved at least a 1-point decrease in their pain intensity score (11-point NRS-3) from baseline, which was defined as a clinically relevant improvement in pain relief and was the minimum target of titration. Titration was continued until at least the minimum target of titration was reached or the patient was taking tapentadol prolonged release $250 \mathrm{mg}$ bid. Doses of tapentadol prolonged release could then be titrated (up to a maximum of $250 \mathrm{mg}$ bid) until patient satisfaction with treatment (5-point VRS) was rated as "good" or better and pain intensity scores (11-point NRS-3) were reduced by 2 or more points from baseline or were no more than 4 . If a dose increase did not lead to further improvement in patient satisfaction (5-point VRS) of at least 1 point or a decrease in the pain intensity score (11-point NRS-3) of at least 1 point at the next study visit, the dose could be decreased to the previous level.

Patients were permitted to take tapentadol immediate release $50 \mathrm{mg}$ ( $\leq$ twice daily; $\geq 4$ hours apart) throughout the 12-week treatment period; the maximum total daily dose of tapentadol (prolonged release and immediate release) was not allowed to exceed $500 \mathrm{mg}$ per day. Tapentadol immediate release was allowed for acute pain episodes due to index pain that had no clear cause, that were associated with increased activity or movement (incidental pain), or that resulted from end-of-dose failure (indicating that the dose of tapentadol prolonged release should be increased); tapentadol immediate release was also permitted for the relief of withdrawal symptoms (eg, hyperalgesia) that might occur during the first 
days of the titration period following discontinuation of prior WHO Step II opioids.

During the 7-week maintenance period, patients continued taking their optimal doses of tapentadol prolonged release and tapentadol immediate release, which were determined during the titration period. All other WHO Step I analgesics, co-analgesics, and medications used to control side effects associated with previous WHO Step II analgesic treatment were continued at the same stable doses unless patients elected to participate in a tapering substudy (Substudy A), in which WHO Step I analgesics or co-analgesics were tapered during the 3-week period from Week 9 to Week 11.

\section{Effectiveness, function, quality- of-life, and tolerability evaluations}

Patients rated their recalled average pain intensity using the 11-point NRS-3 at screening, at baseline, and at all study visits; the pain intensity ratings at baseline and all subsequent study visits referred to the index joint, which was the knee with a higher pain intensity score at screening. The primary endpoint was the change from baseline to Week 6 (the first week of the maintenance period) in average pain intensity on the 11-point NRS-3; the last observation carried forward (LOCF) was used to impute missing pain intensity assessments in the event of early discontinuation. Additional assessments included responder rates 1 and 2; the change from baseline to Weeks 6,8 , and 12 in pain intensity (11-point NRS-3) using observed-case analysis; the patient global impression of change (PGIC); $; 2,28$ the clinician global impression of change (CGIC); $;^{29}$ patient satisfaction with treatment; the Western Ontario and McMaster Universities (WOMAC) osteoarthritis index; ${ }^{30}$ the EuroQol-5 Dimension (EQ-5D) health status questionnaire; ${ }^{31}$ the Short Form-36 (SF-36) health survey; ${ }^{32}$ and the Hospital Anxiety and Depression Scale (HADS).$^{33}$ Total daily doses of tapentadol prolonged release and tapentadol immediate release were also recorded throughout the study.

Responder rate 1 was defined as the percentage of patients with a decrease of at least 1 point in average pain intensity from baseline on the 11-point NRS-3. Responder rate 2 was defined as the percentage of patients with a decrease of at least 1 point in average pain intensity from baseline on the 11-point NRS-3 and an improvement of at least 1 category in patientrated satisfaction with treatment on the 5-point VRS.

The PGIC,,$^{27,28}$ which was completed at each study visit, was used to evaluate patients' impressions of change in their overall condition with trial treatment using a scale from 1 to 7 ( 1 = "very much improved" to 7 = "very much worse").
The CGIC ${ }^{29}$ was also completed at each study visit and was used to evaluate the investigator's impression of the change in a patient's condition from baseline using the same 7-point scale. Patients rated their satisfaction with their previous treatment (WHO Step II analgesics, WHO Step I analgesics, co-analgesics, or no regular analgesic treatment) at screening and baseline using the 5-point VRS, and patients rated their satisfaction with study treatment (tapentadol prolonged release) at each study visit.

The WOMAC osteoarthritis index,,$^{30}$ EQ-5D health status questionnaire, ${ }^{31}$ and SF-36 health survey ${ }^{32}$ were used to evaluate health-related quality of life. The WOMAC osteoarthritis index, ${ }^{30}$ which was completed at screening and baseline and at each study visit, is a validated 24-item questionnaire that is used to evaluate pain, disability, and joint stiffness in patients with knee and hip osteoarthritis; each item was rated on a scale from 0 to 5 , with lower scores indicating lower levels of symptoms. The EQ-5D health status questionnaire and the SF-36 health survey were both completed at screening and baseline, at Weeks 1 and 5, and at all subsequent study visits. The EQ-5D health status questionnaire ${ }^{31}$ includes 5 dimensions of health-related quality of life (mobility, self-care, usual activities, pain/ discomfort, and anxiety/depression), each of which was scored using one of the following levels: "no problems", "some problems", or "extreme problems". The SF-36 health survey ${ }^{32}$ includes 8 dimensions that evaluate bodily pain, general health perceptions, vitality, mental health, and limitations in physical and social activities; all 8 dimensions were scored on a scale from 0 to 100 , with higher scores indicating better health.

Patients completed the HADS at screening and baseline, at Weeks 1 and 5, and at all subsequent study visits. The HADS $^{33}$ consists of 14 questions that evaluate anxiety and depression in medically compromised patients; each question was scored from 0 to 3 and higher scores indicated more severe symptoms of anxiety and depression.

Adverse events (AEs) were recorded throughout the study. An AE was defined as any untoward medical occurrence (including any unfavorable and unintended signs, symptoms, or diseases) in a patient who was enrolled in the study and that occurred during the observation period (prior to receiving the study treatment) or during the active treatment period (after starting the study treatment); an AE was not necessarily related to study treatment. A non-treatment-emergent $\mathrm{AE}$ was defined as any $\mathrm{AE}$ that occurred or was present prior to the start of study treatment; all ongoing medical conditions without a stop date prior to enrollment were recorded as 
non-treatment-emergent AEs during the observation period of this study. A treatment-emergent AE (TEAE) was any AE that newly occurred or worsened in intensity, frequency, or quality after the first intake of study medication. The relationship of TEAEs to tapentadol treatment and the association of AEs with previously or concomitantly received WHO Step I or II analgesics or co-analgesics were evaluated, as described in the Appendix. A serious AE was defined as any $\mathrm{AE}$ that resulted in death, was life-threatening, required in-patient hospitalization or prolongation of an existing hospitalization, resulted in persistent or significant disability or incapacity, resulted in a congenital anomaly or birth defect, or was considered medically important.

\section{Statistical analyses}

Based on a standard deviation (SD) in the mean pain intensity score (11-point NRS-3) of 3, it was estimated that a sample of 73 patients would be required to provide $80 \%$ power for detecting a difference between a clinically relevant mean pain intensity score of 4 and the null hypothesis mean pain intensity score of 5 at Week 6 at $\alpha=0.05$. Given the rejection of the null hypothesis for the primary endpoint, responder rates 1 and 2 were evaluated in a step-wise manner. It was estimated that a sample size of 177 patients would be required to provide $85 \%$ power to detect a difference between a clinically relevant response rate 1 of $60 \%$ and the null hypothesis response rate of $50 \%$ at $\alpha=0.05$.

All patients who took at least 1 dose of study medication were included in the safety population, and all patients who took at least 1 dose of study medication and had 1 or more post-baseline pain intensity assessments were included in the main analysis population, which was used for all effectiveness, quality of life, and functionality analyses. Pain intensity (11-point NRS-3) was evaluated by prior opioid experience; opioid-experienced patients were those who had taken WHO Step II opioid analgesics prior to receiving study treatment and opioid-naïve patients were those who had not taken WHO Step II opioid analgesics prior to receiving study treatment. The primary endpoint (the change from baseline to Week 6 in pain intensity [11-point NRS-3] using the LOCF) was evaluated using a one-sample paired $t$ test, as were the changes from baseline to Weeks 6, 8, and 12 using observed-case analysis.

For the WOMAC osteoarthritis index, the individual item scores for each of the 3 dimensions (pain [5 items], stiffness [2 items], and physical function [17 items]) were summed to produce subscale scores for each dimension; the possible score for the pain subscale ranged from 0 to 20 , the possible score for the stiffness subscale ranged from 0 to 8 , and the possible score for the physical function subscale ranged from 0 to $68 .{ }^{34}$ The 3 subscale scores were then summed to produce a WOMAC global score (possible score, 0-96). For the EQ-5D health status index, a health status index score from $0-1(0=$ "dead" to $1=$ "full health") was derived using weighted responses for each of the individual EQ-5D dimensions. Weighted combinations of the SF-36 subscale scores were used to calculate a physical component summary score and a mental component summary score, both of which have a possible range of scores from 0-100 (where higher scores indicate better health). For the HADS, 7 items were combined to yield an anxiety subscale score (possible score, 0-21) and the remaining 7 items were combined to yield a depression subscale score (possible score, 0-21). For the HADS anxiety and depression subscale scores, a score of 0-7 is considered to be in the normal range, while a score of 8 or more is considered to be suggestive or indicative of the probable presence of anxiety or depression. ${ }^{35}$ A one-sample paired $t$ test was used to analyze the changes from baseline to Week 6 and Week 12 in the 3 WOMAC subscale scores and the WOMAC global score, the changes from baseline to Week 6 and Week 12 in the EQ-5D health status index, the changes from baseline to Week 6 in the 8 SF-36 subscale scores and the 2 SF-36 summary scores, and the changes from baseline to Week 6 and Week 12 in the HADS anxiety and depression subscale scores.

Tapering of WHO Step I analgesics and co-analgesics during Weeks 9 through 12 in Substudy A could theoretically have resulted in pain peaks that could influence effectiveness, function, and quality-of-life results. For that reason, separate analyses were performed for effectiveness, function, and quality-of-life measures for a data set that excluded results from Weeks 9 through 12 for patients who participated in Substudy A and for another data set that included results from Weeks 9 through 12 for these patients. In addition, results of all effectiveness, function, and quality-of-life measures (excluding Weeks 9 through 12 for patients who participated in Substudy A) were evaluated using observed-case analysis and using the LOCF for imputing missing assessments. Separate analyses were performed for the subset of patients who participated in Substudy A $(n=21)$; tapering of WHO Step I analgesics and co-analgesics and the results of pain intensity and responder rate analyses will be briefly described for this subset of patients. The effectiveness, function, and quality-of-life analyses presented in this manuscript are for the data set that excluded results from Weeks 9 through 12 for patients who participated in Substudy A and used 
observed-case analysis unless otherwise specified. Additional effectiveness, function, and quality-of-life results for the population that included results from Weeks 9 through 12 for patients who participated in Substudy A and using the LOCF for imputing missing assessments (excluding Weeks 9 through 12 for patients who participated in Substudy A) are summarized in the Appendix.

\section{Results}

\section{Patients and treatment exposure}

Overall, 224 patients enrolled in the study; 200 patients received at least 1 dose of study medication and were included in the safety population, and 195 patients received at least 1 dose of study medication and had at least 1 postbaseline pain intensity assessment and were included in the main analysis population. In the safety population $(n=200)$, the mean (SD) age was 67.4 (10.81) years, and patients ranged in age from 42 to 94 years. The mean (SD) body mass index in the safety population was $31.9(5.92) \mathrm{kg} / \mathrm{m}^{2}$, and the majority of patients were female $(67.5 \%)$ and white $(98.0 \%)$. Details of the patients' histories of osteoarthritis knee pain, including mean values for the duration of pain, time to first pain-related visit consultation, time off work per year due to pain, number of doctors visited, number of consultations (overall and unplanned), and number of analgesic regimens taken since the pain started, are summarized in Figure 1.

A total of $29.0 \%(58 / 200)$ of patients were taking WHO Step II analgesics during Week -1. The types of WHO Step II analgesics that patients were taking during Week -1 are summarized in Table 1. Overall, 64.5\% (129/200) of patients took WHO Step I analgesics and 17.0\% (34/200) of patients took co-analgesics concomitantly during the study. The most frequently used concomitant WHO Step I analgesics (used by $\geq 2 \%$ of patients) were paracetamol (21.0\% [42/200]), diclofenac (19.0\% [38/200]), ibuprofen (14.0\% [28/200]), etoricoxib (5.5\% [11/200]), celecoxib (4.0\% [8/200]), naproxen (3.0\% [6/200]), and metamizole (2.0\% [4/200]); the most frequently used concomitant coanalgesics (used by $\geq 2 \%$ of patients) were pregabalin $(3.0 \%$ [6/200]) and lidocaine (2.0\% [4/200]).

Overall, $28.0 \%(56 / 200)$ of patients in the safety population discontinued the study early. The reasons for study discontinuation included the following: AEs (12.0\% [24/200]), withdrawal of consent for any reason (6.5\% [13/200]), lack of efficacy $(3.5 \%[7 / 200])$, noncompliance $(0.5 \%$ [1/200]), or other reasons $(5.5 \%$ [11/200]).

In the main analysis population, the mean (SD) total daily dose of tapentadol prolonged release that patients were taking at Week 6 was 256.9 (111.38) mg. The mean (SD) total daily dose of tapentadol immediate release that patients in the main analysis population were taking at Week 6 was 6.7 (21.16) $\mathrm{mg}$. The majority of patients (88.8\% [142/160]) had not taken any tapentadol immediate release during the 3 days prior to the Week 6 visit.

\section{Effectiveness, function, and quality of life}

For the primary endpoint, the mean (SD) pain intensity score (LOCF) decreased from 7.5 (1.08) at baseline to 4.1 (2.11) at Week 6; the mean (SD) change in pain intensity (LOCF) from baseline to Week 6 was -3.4 (2.10; $P<0.0001)$.

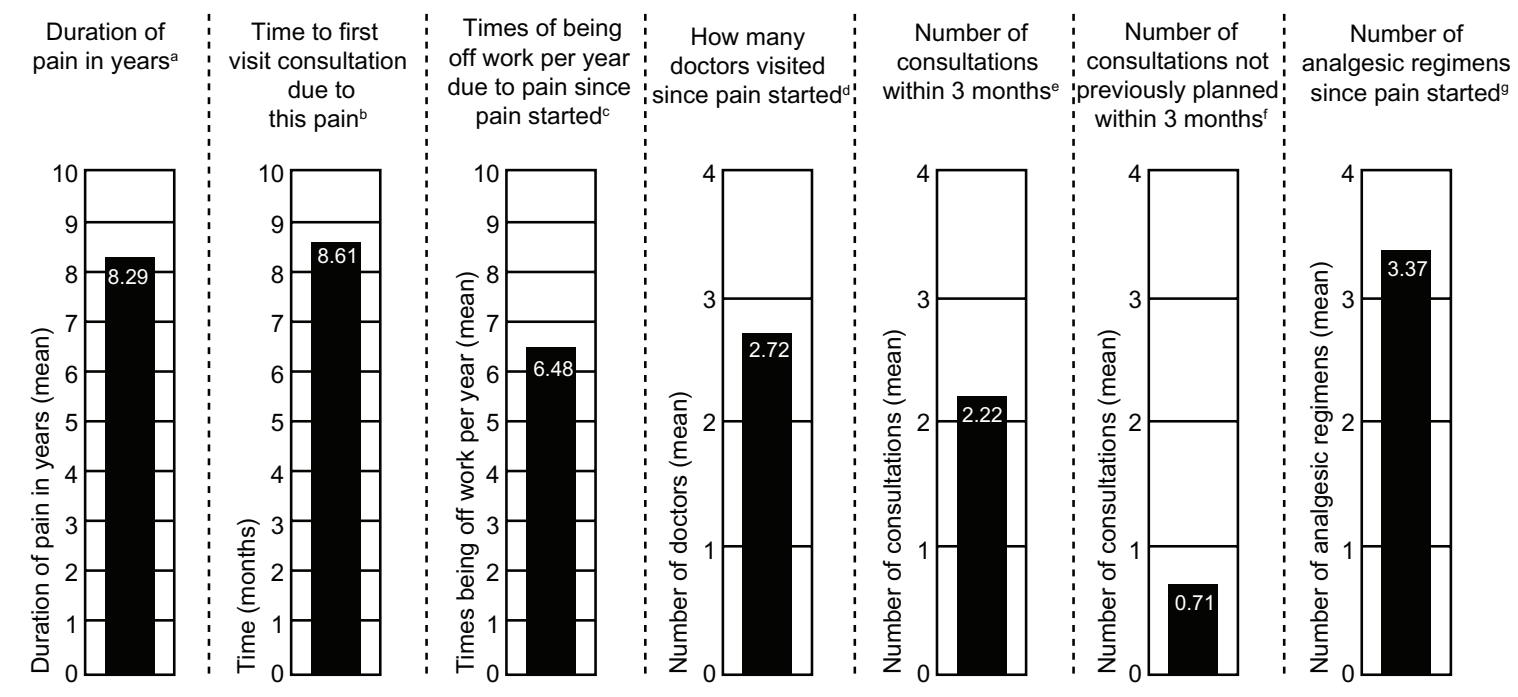

Figure I History of osteoarthritis knee pain (safety population).

Notes: aSD, 7.42 years; 'bD, 28.17 months; 'SD, I4.04 times; 'SD, I.32 doctors; eSD, I.45 consultations; 'SD, I.I0 consultations; ${ }^{8} S D$, 2.53 regimens. Abbreviation: SD, standard deviation. 
Table I WHO Step II analgesics used during Week - I (safety population)

\begin{tabular}{ll}
\hline WHO Step II analgesic, $\mathbf{n}(\%)$ & $\begin{array}{l}\text { Total } \\
(\mathbf{n}=\mathbf{2 0 0})\end{array}$ \\
\hline Tramadol & I7 (8.5) \\
Codeine, paracetamol & $\mathrm{I} 5(7.5)$ \\
Paracetamol, tramadol & $13(6.5)$ \\
Tilidine, naloxone & $5(2.5)$ \\
Dextropropoxyphene, paracetamol & $5(2.5)$ \\
Caffeine, papaver somniferum latex, paracetamol & $2(1.0)$ \\
Other analgesics and antipyretics & $2(1.0)$ \\
\hline
\end{tabular}

Abbreviation: WHO, World Health Organization.

Mean pain intensity over time is shown in Figure 2 for the overall population and opioid-naïve and opioid-experienced patients. In the overall population, mean pain intensity scores improved significantly from baseline to Week 6 (mean [SD] change from baseline, -3.8 [1.94]; $P<0.0001$ ), from baseline to Week $8(-4.2[2.01] ; P<0.0001)$, and from baseline to Week $12(-4.4$ [1.91]; $P<0.0001)$. Significant improvements from baseline in mean pain intensity scores were observed at Weeks 6, 8, and 12, regardless of prior opioid experience (Figure 2). For opioid-naïve patients, the mean (SD) change in pain intensity from baseline to Week 6 was -3.8 (1.90; $P<0.0001)$, from baseline to Week 8 was $-4.1(1.92 ; P<0.0001)$, and from baseline to Week 12 was -4.3 (1.76; $P<0.0001)$. For opioid-experienced patients, the mean (SD) change in pain intensity from baseline to Week 6 was $-3.9(2.08 ; P<0.0001)$, from baseline to Week 8 was $-4.4(2.23 ; P<0.0001)$, and from baseline to Week 12 was $-4.6(2.21 ; P<0.0001)$.

Responder rate 1 (the percentage of patients with a decrease in average pain intensity [11-point NRS-3] from baseline of $\geq 1$ point) was $96.9 \%$ (155/160) at Week 6 and was significantly different from the null hypothesis responder rate 1 of $50 \%(P<0.0001)$. Responder rate 2 (the percentage of patients with a decrease in average pain intensity [11-point NRS-3] from baseline of $\geq 1$ point and an improvement in patient-rated satisfaction with treatment [5-point VRS] of $\geq 1$ category) was $88.8 \%(142 / 160)$ at Week 6 and was significantly different from the null hypothesis responder rate 2 of $50 \%(P<0.0001)$. When the LOCF was used for imputing missing assessments, responder rate 1 was $91.8 \%$ $(179 / 195)$ and responder rate 2 was $78.5 \%(153 / 195)$ at Week $6(P<0.0001$ versus the null hypothesis responder rate $[50 \%]$ for responder rates 1 and 2 ).

At baseline (under prior WHO Step I or II treatment or no regular analgesic treatment), 2.1\% (4/195) of patients reported "excellent", "very good", or "good" satisfaction with treatment; the percentage of patients reporting these satisfaction ratings increased to $89.4 \%(143 / 160)$ at Week 6 and 92.0\% (115/125) at Week 12 (Figure 3). Results of PGIC assessments at Weeks 1, 6, and 12 are summarized in

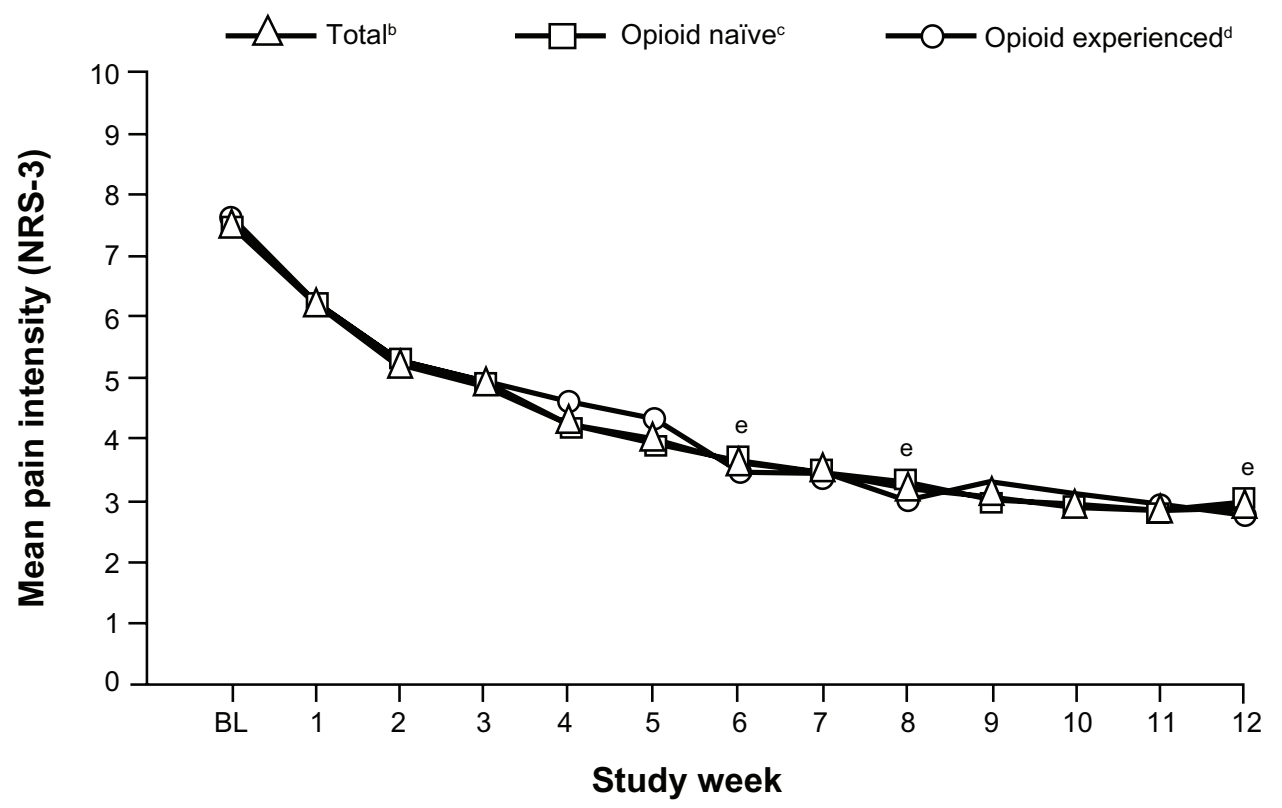

Figure 2 Mean pain intensity (NRS-3) over time for the overall population and opioid-naïve and opioid-experienced patients (main analysis population; observed-case analysis). ${ }^{\text {a }}$ Notes: a Data from Weeks 9 through 12 for patients in the Substudy A population were excluded; 'bDs: BL, I.08; WI, I.70; W2, I.85; W3, I.85; W4, I.84; W5, I.92; W6, I.82; W7, I.83; W8, I.79; W9, I.83; WI0, I.76; WII, I.73; WI2, I.74; 'SDs: BL, I.09; WI, I.66; W2, I.76; W3, I.75; W4, I.68; W5, I.75; W6, I.69; W7, I.7I; W8, I.67; W9, I.53; WI0, I.54; WII, I.47; WI2, I.56; 'SDs: BL, I.06; WI, I.83; W2, 2.II; W3, 2.II; W4, 2.21; W5, 2.27; W6, 2.14; W7, 2.15; W8, 2.07; W9, 2.37; WI0, 2.20; WII, 2.24; $\mathrm{WI} 2$, 2. I0; ${ }^{\mathrm{e}}<0.000 \mathrm{I}$ for the change from $\mathrm{BL}$ for the total population, opioid-naïve patients, and opioid-experienced patients.

Abbreviations: NRS-3, numerical rating scale-3; BL, baseline; SD, standard deviation; W, Week. 


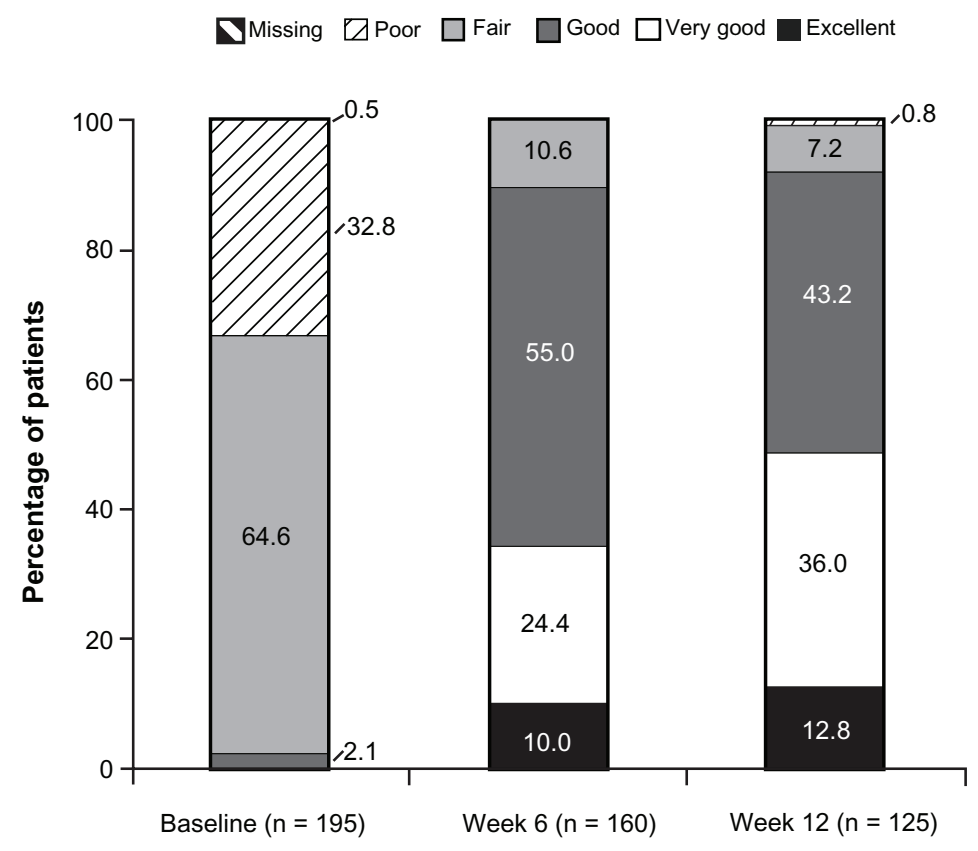

Figure 3 Patient satisfaction with treatment (main analysis population; observed-case analysis). ${ }^{\text {a }}$

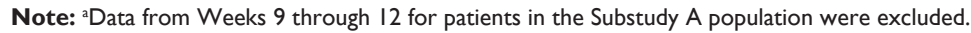

Figure 4. On the PGIC, a rating of "very much improved" or "much improved" was reported by $9.4 \%$ (18/191) of patients at Week 1, 55.6\% (89/160) of patients at Week 6, and 69.6\% $(87 / 125)$ of patients at Week 12. Similar improvements were observed in CGIC ratings over time; a rating of "very much improved" or "much improved" was reported by $12.0 \%$
(23/191) of investigators at Week $1,63.8 \%(102 / 160)$ of investigators at Week 6 , and 76.8\% (96/125) of investigators at Week 12.

The WOMAC osteoarthritis index pain, stiffness, and physical function subscale scores and the WOMAC global score all improved significantly from baseline to Weeks
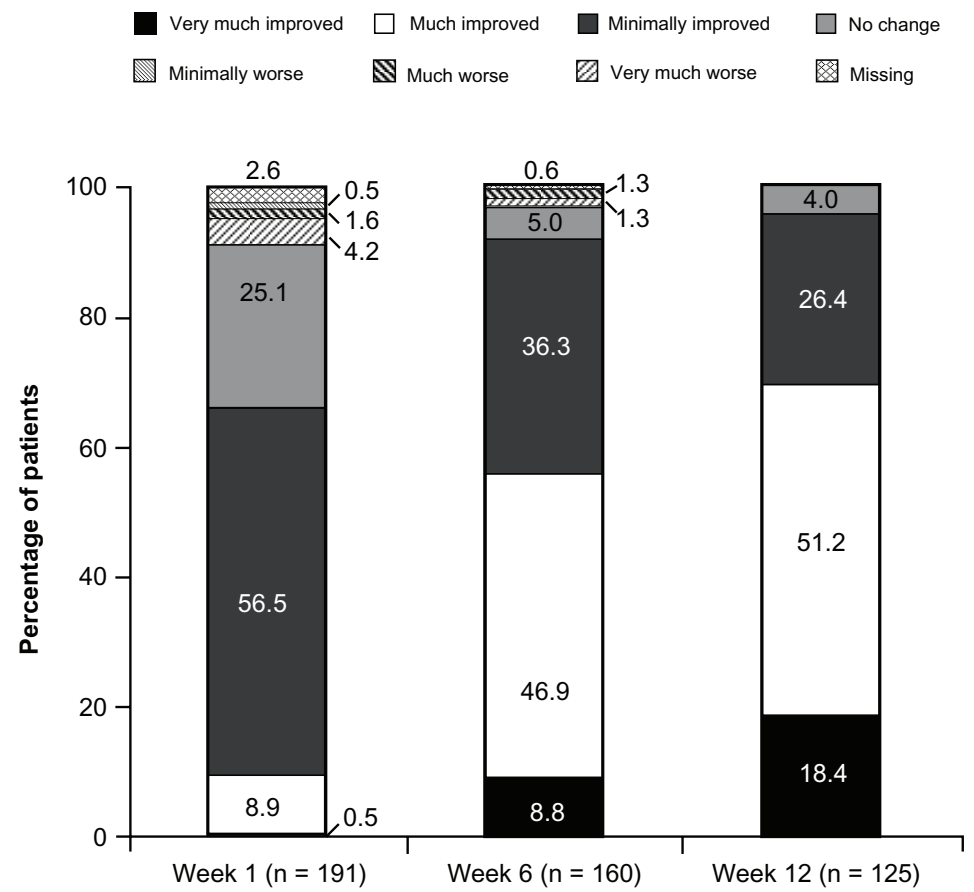

Figure 4 PGIC ratings at Weeks I, 6, and 12 (main analysis population; observed-case analysis). ${ }^{\text {a }}$ Note: a Data from Weeks 9 through 12 for patients in the Substudy A population were excluded. Abbreviation: PGIC, patient global impression of change. 


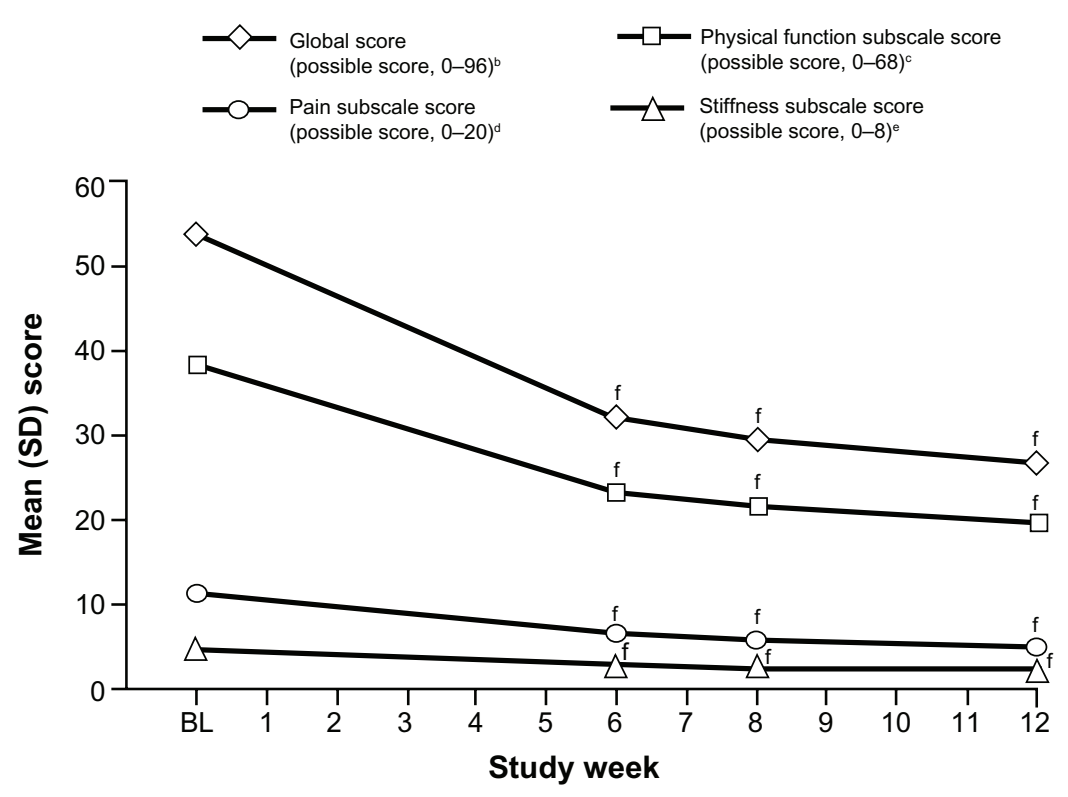

Figure 5 Mean WOMAC osteoarthritis index subscale and global scores over time (main analysis population; observed-case analysis). ${ }^{a}$

Notes: a Data from Weeks 9 through 12 for patients in the Substudy A population were excluded; bSDs: BL, 14.58; W6, 18.80; W8, 17.89; WI2, I8.7I; 'SDs: BL, II.06; W6, 13.84; W8, 13.03; WI2, 13.64; ' ${ }^{S}$ S s: BL, 3.II; W6, 3.93; W8, 3.72; WI2, 3.86; 'eSDs: BL, I.63; W6, I.74; W8, I.68; WI2, I.7I; fP < 0.000I for the change from BL. Abbreviations: WOMAC, Western Ontario and McMaster Universities; SD, standard deviation; BL, baseline; W, Week.

6, 8, and $12(P<0.0001$ for all comparisons; Figure 5). Mean (SD) WOMAC scores at baseline and mean (SD) changes from baseline to Weeks 6, 8, and 12 are summarized in Table 2.

Significant improvements from baseline in the mean EQ-5D health status index score were observed at Weeks 6, 8, and 12. The mean (SD) EQ-5D health status index score was $0.42(0.300)$ at baseline and increased to $0.66(0.203)$ by Week $6,0.67(0.223)$ by Week 8 , and $0.69(0.247)$ by Week 12. The mean (SD) change from baseline in the EQ-5D health status index score was $0.23(0.304)$ at Week $6,0.24$ $(0.323)$ at Week 8 , and $0.27(0.339)$ at Week $12(P<0.0001$ for all comparisons).

Mean SF-36 physical and mental component summary scores improved significantly from baseline to Weeks 6 and $12(P<0.005$ for all comparisons; Table 3$)$. Significant improvements from baseline were also observed in all mean
SF-36 individual domain scores at Week $6(P<0.001$ for all comparisons; Figure 6A) and at Week $12(P<0.05$ for all comparisons; Figure 6B).

Although baseline mean HADS anxiety and depression subscale scores were 7 or less (ie, in the range below the occurrence of signs of clinically manifested anxiety or depression), significant improvements were observed from baseline to Weeks 6,8 , and $12(P<0.0001$ for all comparisons; Appendix Table A7). The mean (SD) HADS anxiety subscale score at baseline was 6.7 (4.14), and the mean (SD) change from baseline was -1.5 (3.29) at Week 6 and -2.2 (3.56) at Week 12. The mean (SD) HADS depression subscale score at baseline was 7.0 (3.73), and the mean (SD) change from baseline was $-1.3(2.95)$ at Week 6 and -1.9 (3.36) at Week 12.

Similar results were shown for pain intensity scores, patient satisfaction with treatment ratings, PGIC ratings,

Table 2 Mean (SD) baseline and changes from baseline in WOMAC scores (main analysis population; observed-case analysis)

\begin{tabular}{|c|c|c|c|c|}
\hline \multirow[t]{2}{*}{ WOMAC score } & \multirow{2}{*}{$\begin{array}{l}\text { Mean (SD) } \\
\text { baseline score } \\
(n=195)\end{array}$} & \multicolumn{3}{|c|}{ Mean (SD) change from baseline } \\
\hline & & $\begin{array}{l}\text { Week } 6 \\
(n=I 59)\end{array}$ & $\begin{array}{l}\text { Week } 8 \\
(n=153)\end{array}$ & $\begin{array}{l}\text { Week I2 } \\
(n=I 25)\end{array}$ \\
\hline Global score $^{a}$ & $53.6(14.58)$ & $-21.0(18.82)^{\mathrm{b}}$ & $-23.7(18.35)^{b}$ & $-27.6(19.52)^{b}$ \\
\hline Pain subscale ${ }^{c}$ & $11.0(3.11)$ & $-4.7(4.38)^{\mathrm{b}}$ & $-5.2(4.33)^{\mathrm{b}}$ & $-6.2(4.45)^{\mathrm{b}}$ \\
\hline Stiffness subscale ${ }^{d}$ & $4.4(1.63)$ & $-1.8(2.03)^{b}$ & $-2.1(1.99)^{\mathrm{b}}$ & $-2.5(2.05)^{b}$ \\
\hline Physical function subscale ${ }^{e}$ & $38.2(11.06)$ & $-14.5(13.40)^{b}$ & $-16.3(12.94)^{b}$ & $-18.9(14.10)^{b}$ \\
\hline
\end{tabular}

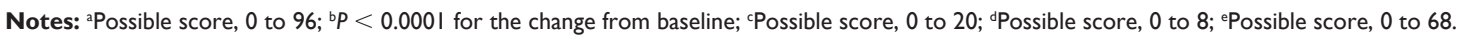

Abbreviations: SD, standard deviation; WOMAC, Western Ontario and McMaster Universities. 
Table 3 Mean (SD) baseline and changes from baseline in SF-36 summary scores (main analysis population; observed-case analysis)

\begin{tabular}{|c|c|c|c|c|}
\hline \multirow[t]{2}{*}{ SF-36 summary score } & \multirow{2}{*}{$\begin{array}{l}\text { Mean }(S D) \\
\text { baseline score } \\
(n=195)\end{array}$} & \multicolumn{3}{|c|}{ Mean (SD) change from baseline } \\
\hline & & $\begin{array}{l}\text { Week } 6 \\
(n=159)\end{array}$ & $\begin{array}{l}\text { Week } 8 \\
(n=I 53)\end{array}$ & $\begin{array}{l}\text { Week I2 } \\
(n=I 25)\end{array}$ \\
\hline Physical component & $28 . I(8.5 I)$ & $7.7(10.20)^{\mathrm{a}}$ & $8.7(9.97)^{\mathrm{a}}$ & $10.7(11.02)^{\mathrm{a}}$ \\
\hline Mental component & $50.7(\mathrm{II} .46)$ & $2.7(10.27)^{\mathrm{a}}$ & $2.0(10.05)^{\mathrm{a}}$ & $3.3(\mid 1.05)^{\mathrm{a}}$ \\
\hline
\end{tabular}

Note: ${ }^{\text {a }} P<0.05$ for the change from baseline.

Abbreviations: SD, standard deviation; SF-36, Short Form-36.

CGIC ratings, WOMAC scores, the EQ-5D health status index score, SF-36 scores, and HADS anxiety and depression subscale scores, regardless of whether results from Weeks 9 through 12 for patients who participated in Substudy A were included or excluded (Appendix Tables A1-A7). Consistent improvements in those measures were also shown whether LOCF was used for imputing missing data or no imputation method was used (observed-case analysis; Appendix Tables A1-A7).

\section{Substudy A}

The majority (81.0\% [17/21]) of patients who enrolled in Substudy A reduced their dose of concomitant WHO Step I analgesics or co-analgesics by $100 \%$ from Week 9 to Week 11 ; an additional $9.5 \%(2 / 21)$ of patients reduced their dose by $50 \%$ and $9.5 \%(2 / 21)$ of patients reduced their dose by $0 \%$. Twenty of the 21 patients in Substudy A tapered a WHO Step I analgesic (ibuprofen; paracetamol; indometacin; diclofenac, misoprostol; diclofenac; etoricoxib; metamizole; or naproxen), and the remaining patient tapered a co-analgesic (duloxetine). Of the patients tapering WHO Step I analgesics, 80.0\% (16/20) tapered their dose by $100 \%$ and $10.0 \%(2 / 20)$ tapered their dose by $50 \%$; the remaining 2 patients (who were both taking paracetamol) did not taper their dose ( $0 \%$ reduction). For the patient who was tapering duloxetine, the dose was tapered by $100 \%$.

For patients in Substudy A, mean (SD) pain intensity decreased significantly from baseline (8.0 [1.02]) to Week 6 (4.2 [0.98]; $P<0.0001$ for the change from baseline); further significant reductions from baseline were observed prior to tapering at Week 8 (4.0 [1.20]; $P<0.0001$ for the change from baseline) and after tapering at Week 12 (3.7 [1.63]; $P<0.0001$ for the change from baseline). Responder rate 1 in Substudy A was $100 \%(21 / 21)$ at Week 6, and remained relatively stable at Week $8(100 \%$ [21/21]) and Week 12 (94.7\% [18/19]; $P<0.0001$ versus the null hypothesis responder rate [50\%] at Weeks 6,8 , and 12 ). Similar results were observed over the course of the study for responder rate 2 in Substudy A (Week 6, 95.2\% [20/21]; Week 8, 100.0\% [21/21]; Week 12, 89.5\% [17/19]; $P \leq 0.0006$ versus the null hypothesis responder rate [50\%] at Weeks 6, 8, and 12).

\section{Tolerability}

No clinically relevant changes from baseline to the end of study treatment were observed in any of the standard safety parameters, including vital sign measures, laboratory values, or physical examination findings.

Overall, 98.0\% (196/200) of patients in the safety population reported non-treatment-emergent AEs; the majority of these AEs were associated with ongoing medical problems.

In the safety population, $71.0 \%(142 / 200)$ of patients reported a TEAE. The most common TEAEs are summarized in Table 4. A total of 57.8\% (243/421) of TEAEs were considered to be at least possibly related to study medication (Table 5). The majority of TEAEs (95.7\% [288/301]) were considered to be of mild or moderate intensity.

Serious TEAEs were reported for $4.0 \%(8 / 200)$ of patients. Serious TEAEs included unstable angina, myocardial infarction, cellulitis, respiratory tract infection, urinary tract infection, radius fracture, back pain, facial palsy, panic attack, and deep vein thrombosis; no individual serious AE was reported for more than 1 patient. TEAEs leading to premature study discontinuation were reported for $12.5 \%$ (25/200) of patients. The reason for one of these AE-related study discontinuations, which occurred due to the serious AEs of urinary tract infection and back pain that were not caused by the study medication, was listed among "other reasons" by the investigator. The most common TEAEs leading to study discontinuation (incidence $\geq 2 \%$ ) included nausea $(2.5 \%$ [5/200]) and dry mouth $(2.0 \%$ [4/200]).

\section{Discussion}

Results of this open-label, phase $3 \mathrm{~b}$ study suggest that tapentadol prolonged release $(50-250 \mathrm{mg}$ bid), in combination with tapentadol immediate release for acute pain episodes due to index pain, is effective and well tolerated for managing severe, chronic osteoarthritis-related knee pain that is inadequately managed with WHO Step I or II opioid analgesics, co-analgesics, or with no regular analgesic treatment. The low overall discontinuation rate and the low discontinuation rate due to AEs was likely related to the use 
A Week $6^{a}$

Total $(n=159)$

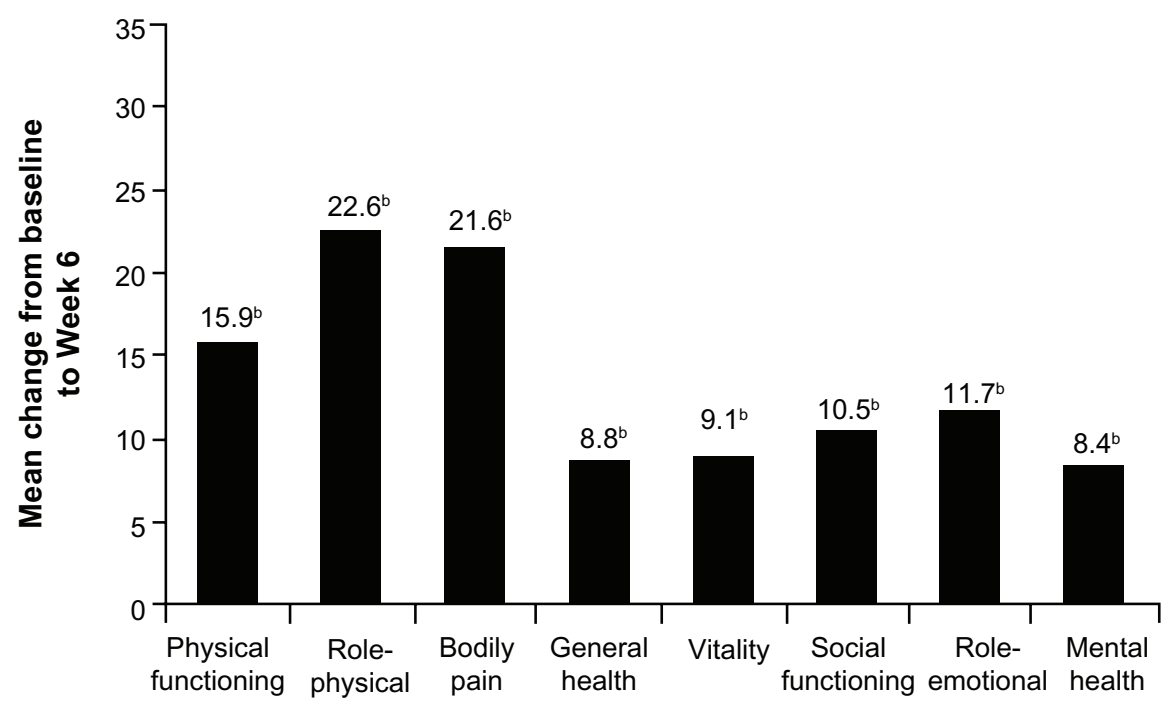

B Week $12^{\mathrm{c}, \mathrm{d}}$

Total $(n=125)$

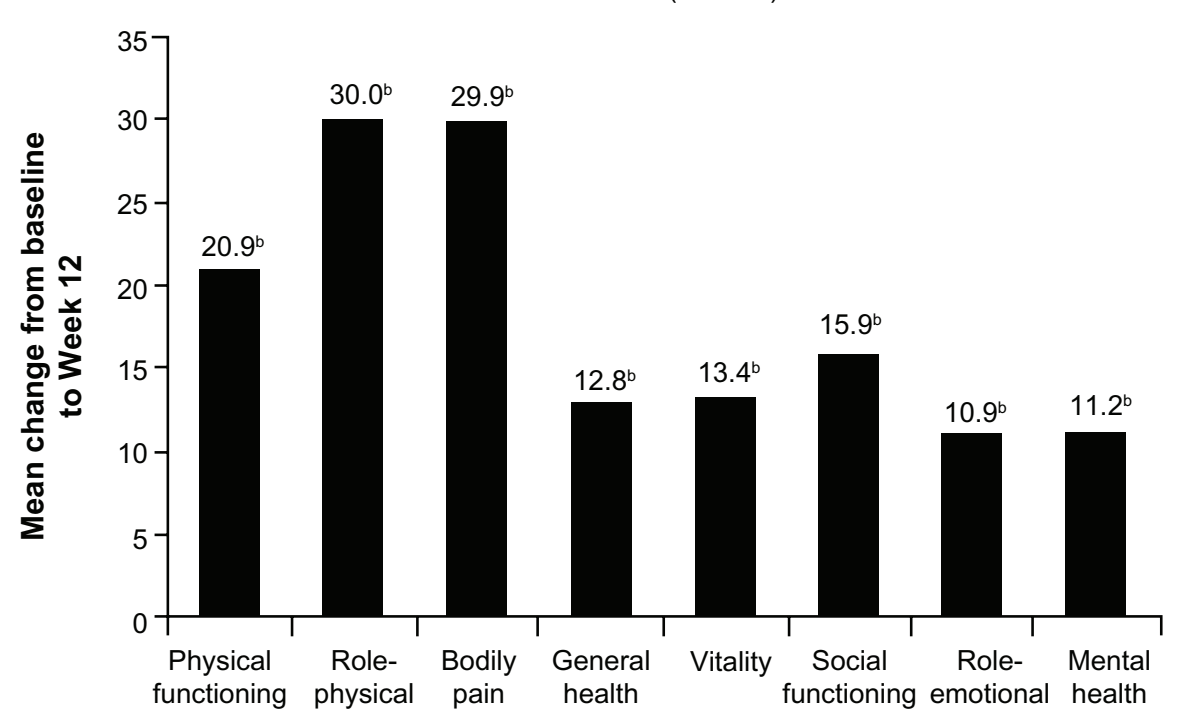

Figure 6 Mean changes in SF-36 domain scores from baseline to (A) Week 6 and (B) Week 12 (main analysis population; observed-case analysis).

Notes: aSD: physical functioning, 23.42; role-physical, 46.29; bodily pain, 23.46; general health, 14.72; vitality, 20.44; social functioning, 26.75; role-emotional, 42.29; mental health, 17.80; ${ }^{\text {b }}<0.05$ for the change from baseline; 'SD: physical functioning, 26.04; role-physical, 46.45; bodily pain, 25.04; general health, I7.65; vitality, 20.92; social functioning, 25.81; role-emotional, 46.91; mental health, 19.58; 'Data from Weeks 9 through 12 for patients in the Substudy A population were excluded.

Abbreviations: SF-36, Short Form-36; SD, standard deviation.

of lower average daily doses of tapentadol prolonged release, which may have resulted from the concomitant use of WHO Step I analgesics or co-analgesics and the 2 complementary mechanisms of action of tapentadol. The concomitant use of WHO Step I analgesics or co-analgesics with tapentadol prolonged release may be common for chronic pain patients in clinical practice; thus, results of this study indicate that tapentadol prolonged release treatment may be associated with good patient adherence to treatment in a clinical setting. Mean pain intensity decreased significantly over the course of the study, regardless of imputation method or prior opioid experience. The use of tapentadol prolonged release alone and in combination with tapentadol immediate release was associated with significant pain relief; however, the majority 
Table 4 Incidences of TEAEs reported by $\geq 5 \%$ of patients (safety population)

\begin{tabular}{ll}
\hline System organ class, $\mathbf{n}(\%)$ & $\begin{array}{l}\text { Total } \\
\left(\mathbf{n}=\mathbf{2 0 0} \mathbf{s}^{\mathbf{a}}\right.\end{array}$ \\
TEAE, $\mathbf{n}(\%)$ & $142(71.0)$ \\
\hline Any TEAE & $77(38.5)$ \\
Gastrointestinal disorders & $26(13.0)$ \\
$\quad$ Nausea & $21(10.5)$ \\
Constipation & $20(10.0)$ \\
Dry mouth & $11(5.5)$ \\
Diarrhea & $10(5.0)$ \\
Vomiting & $55(27.5)$ \\
Nervous system disorders & $24(12.0)$ \\
Dizziness & $14(7.0)$ \\
Somnolence & $13(6.5)$ \\
Headache & $35(17.5)$ \\
General disorders and administration site conditions & $21(10.5)$ \\
Fatigue & $34(I 7.0)$ \\
Infections and infestations & $16(8.0)$ \\
$\quad$ Nasopharyngitis &
\end{tabular}

Note: andicates the number of patients in the safety population, not the number of TEAEs.

Abbreviation: TEAE, treatment-emergent adverse event.

of patients did not require tapentadol immediate release once they had achieved stable dosing with tapentadol prolonged release (by Week 6). The concomitant administration of tapentadol immediate release was not associated with any negative impact on overall tolerability in the current study. Both responder rate 1 (the percentage of patients with a decrease in average pain intensity [11-point NRS-3] of $\geq 1$ ) and responder rate 2 (the percentage of patients with a decrease in average pain intensity of $\geq 1$ and an improvement in patient-rated satisfaction with treatment [5-point VRS] of $\geq 1$ category) were significantly higher than the null hypothesis responder rate of $50 \%$ at Week 6 , regardless of imputation method. Taken together, the improvements in pain intensity and responder rates suggest that tapentadol prolonged release treatment is associated with significant improvements in pain relief relative to prior treatment regimens (WHO Step I or II analgesics or co-analgesics or no regular analgesic treatment), even in patients who rotate directly from WHO Step II analgesics. Similar improvements in pain intensity and responder rates were observed in patients who tapered WHO Step I analgesics or co-analgesics from Weeks 9 to 11 in Substudy A, suggesting that tapering these analgesics and co-analgesics has no relevant therapeutic impact on the effectiveness of tapentadol prolonged release. Tramadol was the most commonly used WHO Step II analgesic during Week -1 ; the significant improvements in mean pain intensity observed in the current study with tapentadol in patients who had failed to respond to treatment with tramadol may be indicative of the higher analgesic strength of tapentadol relative to tramadol.

Both observed-case analysis and LOCF were used to evaluate all major effectiveness, function, and quality-oflife analyses in this study. Observed-case analysis was used for the main results presented throughout this manuscript because results using this method were thought to better represent data observed in clinical practice settings than results of analyses using LOCF. When no imputation method is used (observed-case analysis), data for those patients who discontinue prematurely are omitted; although observed-case analysis may introduce some bias (because discontinuations are typically associated with response to treatment and are

Table 5 Relationship of the most commonly reported (incidence $\geq 5 \%$ ) TEAEs to tapentadol treatment (safety population) ${ }^{\mathrm{a}}$

\begin{tabular}{|c|c|c|c|c|c|c|c|}
\hline $\begin{array}{l}\text { System organ class, } \mathbf{n}(\%) \\
\text { TEAE, } \mathbf{n}(\%)\end{array}$ & $\begin{array}{l}\text { No. of } \\
\text { events }\end{array}$ & $\begin{array}{l}\text { Not } \\
\text { related }\end{array}$ & $\begin{array}{l}\text { Unlikely } \\
\text { related }\end{array}$ & $\begin{array}{l}\text { Possibly } \\
\text { related }\end{array}$ & $\begin{array}{l}\text { Probably or } \\
\text { likely related }\end{array}$ & $\begin{array}{l}\text { Certainly } \\
\text { related }\end{array}$ & Missing \\
\hline Any TEAE & 421 & $143(34.0)$ & $34(8.1)$ & I $74(4 \mid .3)$ & $57(13.5)$ & $12(2.9)$ & $\mathrm{I}(0.2)$ \\
\hline Gastrointestinal disorders & 115 & $14(12.2)$ & $4(3.5)$ & $65(56.5)$ & $26(22.6)$ & $6(5.2)$ & 0 \\
\hline Nausea & 29 & I (3.4) & 0 & $18(62.1)$ & $8(27.6)$ & $2(6.9)$ & 0 \\
\hline Constipation & 22 & 0 & 0 & $9(40.9)$ & II (50.0) & $2(9.1)$ & 0 \\
\hline Dry mouth & 20 & $2(10.0)$ & 0 & $14(70.0)$ & $3(15.0)$ & I (5.0) & 0 \\
\hline Diarrhea & 11 & $2(18.2)$ & $2(18.2)$ & $7(63.6)$ & 0 & 0 & 0 \\
\hline Vomiting & 10 & $2(20.0)$ & $2(20.0)$ & $3(30.0)$ & $2(20.0)$ & I (I0.0) & 0 \\
\hline Nervous system disorders & 68 & II (I6.2) & $2(2.9)$ & $37(54.4)$ & $17(25.0)$ & I (I.5) & 0 \\
\hline Dizziness & 25 & I (4.0) & 0 & $15(60.0)$ & $8(32.0)$ & I $(4.0)$ & 0 \\
\hline Somnolence & 14 & 0 & 0 & $10(71.4)$ & $4(28.6)$ & 0 & 0 \\
\hline Headache & 13 & $3(23.1)$ & I (7.7) & $5(38.5)$ & $4(30.8)$ & 0 & 0 \\
\hline $\begin{array}{l}\text { General disorders and } \\
\text { administration site conditions }\end{array}$ & 38 & $9(23.7)$ & $3(7.9)$ & $19(50.0)$ & $5(13.2)$ & $2(5.3)$ & 0 \\
\hline Fatigue & 22 & $2(9.1)$ & I (4.5) & $16(72.7)$ & $2(9.1)$ & I (4.5) & 0 \\
\hline Infections and infestations & 48 & $43(89.6)$ & $4(8.3)$ & $I(2.1)$ & 0 & 0 & 0 \\
\hline Nasopharyngitis & 21 & $20(95.2)$ & I (4.8) & 0 & 0 & 0 & 0 \\
\hline
\end{tabular}

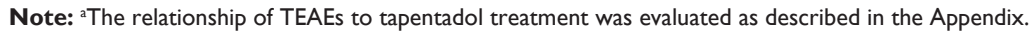

Abbreviation: TEAE, treatment-emergent adverse event. 
not random), the results may be a more accurate reflection of the true study data. In contrast, when LOCF is used for imputing missing data, the missing values are assumed to be the same as the last recorded value, which is unlikely for patients who discontinue. In this study, the results of analyses using LOCF imputation were consistent with those observed when no imputation method was used, supporting the validity of the results. No clinically relevant differences were observed for the major effectiveness, function, and quality-of-life measures, regardless of whether results from Weeks 9 through 12 for patients participating in Substudy A were included or excluded, indicating that tapering of WHO Step I analgesics or co-analgesics in Substudy A had no clinically relevant impact on these measures.

The current study may have been limited by the lack of a placebo or active comparator. However, study results were in line with those observed in a previous randomized, doubleblind, placebo- and active-controlled study that evaluated the efficacy and safety of 15 weeks (3-week titration period and 12-week maintenance period) of tapentadol prolonged release (100-250 mg bid) treatment for moderate to severe, chronic osteoarthritis-related knee pain. ${ }^{24}$ Due to the specific selection criteria, the population in a clinical study may not be completely representative of the population observed in a general clinical practice setting, which could include patients with severe osteoarthritis knee pain who have multiple co-morbidities or advanced illnesses; these patients have to be excluded from a clinical trial because of ethical safety-related concerns based on precautions, warnings, and contraindications according to the Summaries of Product Characteristics for compounds used in the trial or to avoid confounding factors that could potentially bias trial results (eg, conditions other than the index pain under evaluation that are associated with pain or a major negative impact on quality-of-life or function parameters). For that reason, caution should be exercised in interpreting these results for the general population of patients with osteoarthritis pain.

There is a growing body of evidence that supports the role of disturbed descending pain inhibition in osteoarthritis pain. ${ }^{13,14,37,38}$ The prevalence of chronic pain following joint replacement surgery ranges from $27 \%$ to $44 \% 0^{39-41}$; central sensitization associated with disturbed descending pain inhibition is thought to contribute to this pain following joint replacement. ${ }^{42}$ Continuous mechanical stimulation resulting from degradation of the cartilage also contributes to osteoarthritis pain. ${ }^{43}$ The $\mu$-opioid agonist activity of tapentadol may be more effective at controlling the nociceptive pain arising from cartilage degradation, while the noradrenaline reuptake inhibitor activity of tapentadol may be more effective for reestablishing descending inhibitory pain pathways.

The significant improvements in pain intensity observed with tapentadol treatment were accompanied by significant improvements from baseline to Weeks 6 and 12 in the WOMAC pain, stiffness, physical function, and global scores, as well as in the SF-36 index and summary scores and the EQ-5D health status index score in patients with severe, chronic osteoarthritis-related knee pain. By Week 6, the mean change from baseline in the EQ-5D health status index score $(0.23)$ exceeded the threshold for a minimally clinically important difference $(0.074)^{44}$ and stayed above this threshold for the remainder of the study. Clinically meaningful improvements ( $\geq 5$ points $)^{45}$ from baseline were also observed in mean scores for all 8 SF-36 individual domains and the physical component summary at Weeks 6 and 12. Treatment with tapentadol was also associated with significant improvements from baseline in mean HADS anxiety and depression subscale scores at Weeks 6 and 12. The improvements observed in HADS anxiety and depression subscale scores were of lesser clinical relevance because baseline HADS anxiety and depression subscale scores were 7 or less and did not indicate the presence of clinically manifested anxiety and depression, respectively. These improvements in measures of health status, quality of life, pain, stiffness, and physical function were matched by corresponding improvements in patients' and clinicians' global impressions of change in patients' overall conditions and patient-rated satisfaction with treatment.

In a meta-analysis ${ }^{8}$ of 18 placebo-controlled studies of opioids for the management of osteoarthritis pain, opioid treatment was associated with significant improvements in pain intensity compared with placebo (pooled effect size versus placebo, -0.79 [95\% confidence interval, -0.98 to -0.59]) and small improvements in function, based on the WOMAC physical function subscale $(-0.31$ [ -0.39 to -0.24$])$. However, patient compliance with treatment was limited by low tolerability, with approximately $25 \%$ of patients discontinuing treatment because of AEs. ${ }^{8}$ Gastrointestinal TEAEs, specifically nausea, vomiting, and constipation, may be particularly problematic for patients taking long-term opioid treatment for chronic pain. In a survey of 316 patients with chronic pain who were being treated with opioid analgesics, gastrointestinal side effects were reported as being among the most bothersome side effects and medication preference was largely determined by avoiding the occurrence of nausea and vomiting. ${ }^{46}$ In a randomized, double-blind, placebo-controlled study ${ }^{47}$ of oxycodone controlled release (average total daily 
dose, $44 \mathrm{mg}$ ) for the management of moderate to severe osteoarthritis pain, nausea, vomiting, and constipation were reported for $41.1 \%, 12.5 \%$, and $48.2 \%$ of patients, respectively, and $36 \%$ of patients withdrew from the study because of AEs. In contrast, nausea, vomiting, and constipation were reported by $13.0 \%, 5.0 \%, 10.5 \%$ of patients, respectively, in the current study and only $12.0 \%$ of patients withdrew from the study because of AEs.

Results of the current open-label phase $3 \mathrm{~b}$ study support those of other previous randomized, placebo- and/ or active-controlled studies in patients with moderate to severe, chronic osteoarthritis pain, ${ }^{25,26}$ and suggest that tapentadol prolonged release (50-250 mg bid) with tapentadol immediate release on-demand is effective and well tolerated for the management of severe, chronic osteoarthritisrelated knee pain in patients with inadequately managed pain, including those rotating directly from WHO Step II analgesics.

\section{Acknowledgments}

Editorial support for the writing of this manuscript was provided by Megan Knagge, PhD, of MedErgy, and was funded by Medical Affairs, Grünenthal Europe \& Australia, Grünenthal GmbH, Aachen, Germany. The authors retained full editorial control over the content of the manuscript.

\section{Disclosure}

IS and MM are employees of Grünenthal GmbH. JCB has received funding from Grünenthal, Abbott, Genévrier, Genzyme, MSD, Pfizer, Roche, Roche Chugai, UCB, and Wyeth, and has served as a speaker for Abbott, Expanscience, Genévrier, MSD, Procter \& Gamble, Servier, and Wyeth. JCA has served as a consultant on advisory boards for Grünenthal. JK has no conflicts to disclose.

\section{References}

1. Lawrence RC, Felson DT, Helmick CG, et al. Estimates of the prevalence of arthritis and other rheumatic conditions in the United States. Part II. Arthritis Rheum. 2008;58(1):26-35.

2. Sakalauskiene G, Jauniskiene D. Osteoarthritis: etiology, epidemiology, impact on the individual and society and the main principles of management. Medicina (Kaunas). 2010;46(11):790-797.

3. Kopec JA, Rahman MM, Berthelot JM, et al. Descriptive epidemiology of osteoarthritis in British Columbia, Canada. J Rheumatol. 2007;34(2): 386-393.

4. Martel-Pelletier J, Pelletier JP. Is osteoarthritis a disease involving only cartilage or other articular tissues? Eklem Hastalik Cerrahisi. 2010; 21(1):2-14.

5. Breedveld FC. Osteoarthritis - the impact of a serious disease. Rheumatology (Oxford). 2004;43(Suppl 1):i4-i8.

6. Axford J, Heron C, Ross F, Victor CR. Management of knee osteoarthritis in primary care: pain and depression are the major obstacles. JPsychosom Res. 2008;64(5):461-467.
7. Zhang W, Moskowitz RW, Nuki G, et al. OARSI recommendations for the management of hip and knee osteoarthritis, Part II: OARSI evidence-based, expert consensus guidelines. Osteoarthritis Cartilage. 2008;16(2):137-162.

8. Avouac J, Gossec L, Dougados M. Efficacy and safety of opioids for osteoarthritis: a meta-analysis of randomized controlled trials. Osteoarthritis Cartilage. 2007;15(8):957-965.

9. Caldwell JR, Rapoport RJ, Davis JC, et al. Efficacy and safety of a once-daily morphine formulation in chronic, moderate-to-severe osteoarthritis pain: results from a randomized, placebo-controlled, double-blind trial and an open-label extension trial. J Pain Symptom Manage. 2002;23(4):278-291.

10. Matsumoto AK, Babul N, Ahdieh H. Oxymorphone extendedrelease tablets relieve moderate to severe pain and improve physical function in osteoarthritis: results of a randomized, double-blind, placebo- and active-controlled phase III trial. Pain Med. 2005;6(5): 357-366.

11. Nicholson B. Benefits of extended-release opioid analgesic formulations in the treatment of chronic pain. Pain Pract. 2009;9(1):71-81.

12. Wieland HA, Michaelis M, Kirschbaum BJ, Rudolphi KA. Osteoarthritis - an untreatable disease? Nat Rev Drug Discov. 2005; 4(4):331-344.

13. Arendt-Nielsen L, Nie H, Laursen MB, et al. Sensitization in patients with painful knee osteoarthritis. Pain. 2010;149(3):573-581.

14. Woolf CJ. Central sensitization: implications for the diagnosis and treatment of pain. Pain. 2011;152(Supp1 3):S2-S15.

15. Management of chronic pain syndromes: issues and interventions. Pain Med. 2005;6(Supp1 1):S1-S20.

16. Curatolo M, Arendt-Nielsen L, Petersen-Felix S. Central hypersensitivity in chronic pain: mechanisms and clinical implications. Phys Med Rehabil Clin NAm. 2006;17(2):287-302.

17. Sommer C. Is serotonin hyperalgesic or analgesic? Curr Pain Headache Rep. 2006;10(2):101-106.

18. Suzuki R, Rygh LJ, Dickenson AH. Bad news from the brain: descending 5-HT pathways that control spinal pain processing. Trends Pharmacol Sci. 2004;25(12):613-617.

19. Benyamin R, Trescot AM, Datta S, et al. Opioid complications and side effects. Pain Physician. 2008;11(Suppl 2):S105-S120.

20. Furlan AD, Sandoval JA, Mailis-Gagnon A, Tunks E. Opioids for chronic noncancer pain: a meta-analysis of effectiveness and side effects. CMAJ. 2006;174(11):1589-1594.

21. Porreca F, Ossipov MH. Nausea and vomiting side effects with opioid analgesics during treatment of chronic pain: mechanisms, implications, and management options. Pain Med. 2009;10(4):654-662.

22. Tzschentke TM, Christoph T, Kögel B, et al. (-)-(1R,2R)-3(3-Dimethylamino-1-ethyl-2-methyl-propyl)-phenol hydrochloride (tapentadol $\mathrm{HCl}$ ): a novel $\mu$-opioid receptor agonist/norepinephrine reuptake inhibitor with broad-spectrum analgesic properties. J Pharmacol Exp Ther. 2007;323(1):265-276.

23. Tzschentke TM, De Vry J, Terlinden R, et al. Tapentadol hydrochloride. Analgesic, mu-opioid receptor agonist, noradrenaline reuptake inhibitor. Drugs Future. 2006;31(12):1053-1061.

24. Afilalo M, Etropolski MS, Kuperwasser B, et al. Efficacy and safety of tapentadol extended release compared with oxycodone controlled release for the management of moderate to severe chronic pain related to osteoarthritis of the knee: a randomized, double-blind, placebo- and active-controlled phase III study. Clin Drug Investig. 2010;30(8): 489-505.

25. Lange B, Kuperwasser B, Okamoto A, et al. Efficacy and safety of tapentadol prolonged release for chronic osteoarthritis pain and low back pain. Adv Ther. 2010;27(6):381-399.

26. Wild JE, Grond S, Kuperwasser B, et al. Long-term safety and tolerability of tapentadol extended release for the management of chronic low back pain or osteoarthritis pain. Pain Pract. 2010;10(5):416-427.

27. Dworkin RH, Turk DC, Farrar JT, et al. Core outcome measures for chronic pain clinical trials: IMMPACT recommendations. Pain. 2005; 113(1-2):9-19. 
28. Farrar JT, Young JP Jr, LaMoreaux L, Werth JL, Poole RM. Clinical importance of changes in chronic pain intensity measured on an 11-point numerical pain rating scale. Pain. 2001;94(2):149-158.

29. Schneider LS, Olin JT, Doody RS, et al. Validity and reliability of the Alzheimer's Disease Cooperative Study-Clinical Global Impression of Change. The Alzheimer's Disease Cooperative Study. Alzheimer Dis Assoc Disord. 1997;11 Suppl 2:S22-S32.

30. Bellamy N, Buchanan WW, Goldsmith CH, Campbell J, Stitt LW. Validation study of WOMAC: a health status instrument for measuring clinically important patient relevant outcomes to antirheumatic drug therapy in patients with osteoarthritis of the hip or knee. J Rheumatol. 1988;15(12):1833-1840

31. Selai CE, Trimble MR, Price MJ, Remak E. Evaluation of health status in epilepsy using the EQ-5D questionnaire: a prospective, observational, 6-month study of adjunctive therapy with anti-epileptic drugs. Curr Med Res Opin. 2005;21(5):733-739.

32. Ware JE Jr, Sherbourne CD. The MOS 36-item Short-Form Health Survey (SF-36). I. Conceptual framework and item selection. Med Care. 1992;30(6):473-483.

33. Bjelland I, Dahl AA, Haug TT, Neckelmann D. The validity of the Hospital Anxiety and Depression Scale. An updated literature review. J Psychosom Res. 2002;52(2):69-77.

34. Bellamy N. WOMAC Osteoarthritis Index: User Guide IV. Queensland, Australia: WOMAC; 2000.

35. Snaith RP. The Hospital Anxiety And Depression Scale. Health Qual Life Outcomes. 2003;1:29.

36. Zigmond AS, Snaith RP. The hospital anxiety and depression scale. Acta Psychiatr Scand. 1983;67(6):361-370.

37. Gwilym SE, Keltner JR, Warnaby CE, et al. Psychophysical and functional imaging evidence supporting the presence of central sensitization in a cohort of osteoarthritis patients. Arthritis Rheum. 2009;61(9):1226-1234.
38. Hochman JR, French MR, Bermingham SL, Hawker GA. The nerve of osteoarthritis pain. Arthritis Care Res (Hoboken). 2010;62(7): 1019-1023.

39. Nikolajsen L, Brandsborg B, Lucht U, Jensen TS, Kehlet H. Chronic pain following total hip arthroplasty: a nationwide questionnaire study. Acta Anaesthesiol Scand. 2006;50(4):495-500.

40. Puolakka PA, Rorarius MG, Roviola M, Puolakka TJ, Nordhausen K, Lindgren L. Persistent pain following knee arthroplasty. Eur J Anaesthesiol. 2010;27(5):455-460.

41. Wylde V, Hewlett S, Learmonth ID, Dieppe P. Persistent pain after joint replacement: prevalence, sensory qualities, and postoperative determinants. Pain. 2011;152(3):566-572.

42. Lundblad H, Kreicbergs A, Jansson KA. Prediction of persistent pain after total knee replacement for osteoarthritis. J Bone Joint Surg Br. 2008;90(2):166-171.

43. Loeser RF. Molecularmechanisms of cartilage destruction in osteoarthritis. J Musculoskelet Neuronal Interact. 2008;8(4):303-306.

44. Walters SJ, Brazier JE. Comparison of the minimally important difference for two health state utility measures: EQ-5D and SF-6D. Qual Life Res. 2005;14(6):1523-1532.

45. Samsa G, Edelman D, Rothman ML, Williams GR, Lipscomb J, Matchar D. Determining clinically important differences in health status measures: a general approach with illustration to the Health Utilities Index Mark II. Pharmacoeconomics. 1999;15(2):141-155.

46. Gregorian RS Jr, Gasik A, Kwong WJ, Voeller S, Kavanagh S. Importance of side effects in opioid treatment: a trade-off analysis with patients and physicians. J Pain. 2010;11(11):1095-1108.

47. Markenson JA, Croft J, Zhang PG, Richards P. Treatment of persistent pain associated with osteoarthritis with controlled-release oxycodone tablets in a randomized controlled clinical trial. Clin J Pain. 2005;21(6) $524-535$. 


\section{Appendix}

\section{Determining the relationship of AEs}

to tapentadol and the association of AEs with previously or concomitantly received WHO Step I or II analgesics or co-analgesics

An AE was considered to be not related to study treatment if there was sufficient evidence to accept that there was no causal relationship to study medication administration (ie, no temporal relationship to study medication administration or another cause was demonstrated for the AE) and was considered to be unlikely related to study treatment if there was insufficient evidence to accept that there was no causal relationship to study medication administration, but there was no evidence to suggest a causal relationship (eg, a temporal relationship to study medication administration that makes a causal relationship improbable, and other drugs, chemicals, or underlying disease provide plausible explanations). An AE was considered to be possibly related to the study medication if there was limited evidence suggesting a causal relationship (eg, reasonable temporal relationship between study medication administration and the AE, but the AE could also be explained by concurrent disease or other drugs); probably or likely related to the study medication if there was sufficient evidence to suggest a causal relationship (eg, reasonable temporal relationship between study medication administration and the $\mathrm{AE}$, and the $\mathrm{AE}$ was unlikely to be related to a concurrent disease or other drug); and certainly related to the study medication if there was clear evidence for a causal relationship (eg, reasonable temporal relationship between study medication administration and the $\mathrm{AE}$, and the $\mathrm{AE}$ could not be explained by concurrent disease or other drugs). All AEs were also evaluated to determine an association with any of the previously or concomitantly received WHO Step I or II analgesics or co-analgesics; if any of the AEs could be at least possibly associated with any of the analgesics or co-analgesics, the causality was recorded.

Table A I Mean (SD) pain intensity scores (I I-point NRS-3) overall and by prior opioid experience at baseline and at Weeks 6 and I2 using observed-case analysis (with and without the Week 9-12 data for the Substudy A population) and using the LOCF (without the Week 9-12 data for the Substudy A population) - main analysis population

\begin{tabular}{|c|c|c|c|c|c|c|}
\hline \multirow[t]{4}{*}{ Population } & \multirow[t]{4}{*}{ Baseline } & \multicolumn{3}{|c|}{ Observed-case analysis } & \multicolumn{2}{|l|}{ LOCF } \\
\hline & & \multirow[t]{3}{*}{ Week 6} & \multicolumn{2}{|l|}{ Week I 2} & \multirow[t]{3}{*}{ Week 6} & \multirow{3}{*}{$\begin{array}{l}\text { Week I } 2 \\
\text { Without } \\
\text { Substudy A }\end{array}$} \\
\hline & & & Without & With & & \\
\hline & & & Substudy A & Substudy A & & \\
\hline \multirow[t]{2}{*}{ Total } & $(n=195)$ & $(n=160)$ & $(n=125)$ & $(n=144)$ & $(n=193)$ & $(n=172)$ \\
\hline & $7.5(1.08)$ & $3.6(1.82)^{\mathrm{a}}$ & $2.9(1.74)^{\mathrm{a}}$ & $3.0(1.74)^{\mathrm{a}}$ & $4.1(2.11)^{a}$ & $3.7(2.28)^{\mathrm{a}}$ \\
\hline \multirow[t]{2}{*}{ Opioid naïve } & $(n=139)$ & $(n=116)$ & $(n=86)$ & $(n=104)$ & $(n=139)$ & $(n=119)$ \\
\hline & $7.5(1.09)$ & $3.7(1.69)^{\mathrm{a}}$ & $3.0(1.56)^{\mathrm{a}}$ & $3.1(1.55)^{\mathrm{a}}$ & $4.1(1.99)^{\mathrm{a}}$ & $3.7(2.15)^{\mathrm{a}}$ \\
\hline \multirow[t]{2}{*}{ Opioid experienced } & $(n=56)$ & $(n=44)$ & $(n=39)$ & $(n=40)$ & $(n=54)$ & $(n=53)$ \\
\hline & $7.6(1.06)$ & $3.5(2.14)^{\mathrm{a}}$ & $2.8(2.10)^{\mathrm{a}}$ & $2.9(2.17)^{\mathrm{a}}$ & $4.1(2.4 I)^{\mathrm{a}}$ & $3.7(2.57)^{\mathrm{a}}$ \\
\hline
\end{tabular}

Note: ${ }^{p} P<0.0001$ for the change from baseline.

Abbreviations: SD, standard deviation; NRS-3, numerical rating scale-3; LOCF, last observation carried forward.

Table A2 Patient satisfaction with treatment ratings at baseline and at Weeks 6 and 12 using observed-case analysis (with and without the Week 9-12 data for the Substudy A population) and using the LOCF (without the Week 9-12 data for the Substudy A population) - main analysis population

\begin{tabular}{|c|c|c|c|c|c|c|}
\hline \multirow{5}{*}{$\begin{array}{l}\text { Satisfaction } \\
\text { rating, n (\%) }\end{array}$} & \multirow{5}{*}{$\begin{array}{l}\text { Baseline } \\
(n=195)\end{array}$} & \multicolumn{3}{|c|}{ Observed-case analysis } & \multicolumn{2}{|l|}{ LOCF } \\
\hline & & \multirow{4}{*}{$\begin{array}{l}\text { Week } 6 \\
(n=160)\end{array}$} & \multicolumn{2}{|l|}{ Week I 2} & \multirow{4}{*}{$\begin{array}{l}\text { Week } 6 \\
(n=193)\end{array}$} & \multirow{4}{*}{$\begin{array}{l}\text { Week I2 } \\
\text { Without } \\
\text { Substudy A } \\
(\mathrm{n}=\text { I 72) }\end{array}$} \\
\hline & & & Without & With & & \\
\hline & & & Substudy A & Substudy A & & \\
\hline & & & $(n=125)$ & $(n=144)$ & & \\
\hline Excellent & 0 & $16(10.0)$ & $16(12.8)$ & I 7 ( I I.8) & $16(8.3)$ & $17(9.9)$ \\
\hline Very good & 0 & $39(24.4)$ & $45(36.0)$ & $52(36.1)$ & $4 \mid(2 \mid .2)$ & $47(27.3)$ \\
\hline Good & $4(2.1)$ & $88(55.0)$ & $54(43.2)$ & $63(43.8)$ & 95 (49.2) & $69(40.1)$ \\
\hline Fair & $126(64.6)$ & $17(10.6)$ & $9(7.2)$ & II (7.6) & $29(15.0)$ & $26(15.1)$ \\
\hline Poor & $64(32.8)$ & 0 & I (0.8) & I (0.7) & $12(6.2)$ & $13(7.6)$ \\
\hline Missing & I $(0.5)$ & 0 & 0 & 0 & 0 & 0 \\
\hline
\end{tabular}

Abbreviation: LOCF, last observation carried forward. 
Table A3 PGIC and CGIC ratings at baseline and at Weeks 6 and 12 using observed-case analysis (with and without the Week 9-12 data for the Substudy A population) and using the LOCF (without the Week 9-12 data for the Substudy A population) - main analysis population

\begin{tabular}{|c|c|c|c|c|c|}
\hline \multirow[t]{3}{*}{ Rating, n (\%) } & \multicolumn{3}{|c|}{ Observed-case analysis } & \multicolumn{2}{|l|}{ LOCF } \\
\hline & \multirow{2}{*}{$\begin{array}{l}\text { Week } 6 \\
(n=160)\end{array}$} & \multicolumn{2}{|l|}{ Week I2 } & \multirow{2}{*}{$\begin{array}{l}\text { Week } 6 \\
(n=193)\end{array}$} & \multirow{2}{*}{$\begin{array}{l}\text { Week I2 } \\
\text { Without } \\
\text { Substudy A } \\
(\mathrm{n}=172)\end{array}$} \\
\hline & & $\begin{array}{l}\text { Without } \\
\text { Substudy A } \\
(n=125)\end{array}$ & $\begin{array}{l}\text { With } \\
\text { Substudy A } \\
(n=144)\end{array}$ & & \\
\hline \multicolumn{6}{|l|}{ PGIC } \\
\hline Very much improved & $14(8.8)$ & $23(18.4)$ & $24(16.7)$ & $14(7.3)$ & $24(14.0)$ \\
\hline Much improved & $75(46.9)$ & $64(5 \mid .2)$ & $79(54.9)$ & 79 (40.9) & $71(4 I .3)$ \\
\hline Minimally improved & $58(36.3)$ & $33(26.4)$ & $35(24.3)$ & $67(34.7)$ & $48(27.9)$ \\
\hline No change & $8(5.0)$ & $5(4.0)$ & $6(4.2)$ & $18(9.3)$ & $17(9.9)$ \\
\hline Minimally worse & $2(1.3)$ & 0 & 0 & $7(3.6)$ & $5(2.9)$ \\
\hline Much worse & $2(1.3)$ & 0 & 0 & $5(2.6)$ & $4(2.3)$ \\
\hline Very much worse & 0 & 0 & 0 & $3(1.6)$ & $3(1.7)$ \\
\hline Missing & $\mathrm{I}(0.6)$ & 0 & 0 & - & - \\
\hline \multicolumn{6}{|l|}{ CGIC } \\
\hline Very much improved & $14(8.8)$ & $28(22.4)$ & $29(20.1)$ & $14(7.3)$ & $29(16.9)$ \\
\hline Much improved & $88(55.0)$ & $68(54.4)$ & $83(57.6)$ & $93(48.2)$ & 79 (45.9) \\
\hline Minimally improved & $47(29.4)$ & $27(21.6)$ & $28(19.4)$ & $56(29.0)$ & $41(23.8)$ \\
\hline No change & $7(4.4)$ & $2(1.6)$ & $4(2.8)$ & $15(7.8)$ & $12(7.0)$ \\
\hline Minimally worse & $2(1.3)$ & 0 & 0 & $10(5.2)$ & $8(4.7)$ \\
\hline Much worse & $\mathrm{I}(0.6)$ & 0 & 0 & $3(1.6)$ & $2(1.2)$ \\
\hline Very much worse & I (0.6) & 0 & 0 & $2(1.0)$ & I $(0.6)$ \\
\hline Missing & 0 & 0 & 0 & - & - \\
\hline
\end{tabular}

Abbreviations: PGIC, patient global impression of change; CGIC, clinician global impression of change; LOCF, last observation carried forward.

Table A4 Mean (SD) WOMAC scores at baseline and at Weeks 6 and 12 using observed-case analysis (with and without the Week 9-12 data for the Substudy A population) and using the LOCF (without the Week 9-12 data for the Substudy A population) - main analysis population

\begin{tabular}{|c|c|c|c|c|c|c|}
\hline \multirow[t]{3}{*}{ WOMAC score } & \multirow{3}{*}{$\begin{array}{l}\text { Baseline } \\
(n=195)\end{array}$} & \multicolumn{3}{|c|}{ Observed-case analysis } & \multicolumn{2}{|l|}{ LOCF } \\
\hline & & \multirow{2}{*}{$\begin{array}{l}\text { Week } 6 \\
(n=159)\end{array}$} & \multicolumn{2}{|l|}{ Week I 2} & \multirow{2}{*}{$\begin{array}{l}\text { Week } 6 \\
(n=185)\end{array}$} & \multirow{2}{*}{$\begin{array}{l}\text { Week I2 } \\
\text { Without } \\
\text { Substudy A } \\
(n=164)\end{array}$} \\
\hline & & & $\begin{array}{l}\text { Without } \\
\text { Substudy A } \\
(n=125)\end{array}$ & $\begin{array}{l}\text { With } \\
\text { Substudy A } \\
(n=144)\end{array}$ & & \\
\hline Global score ${ }^{a}$ & $53.6(14.58)$ & $32.1(18.80)^{b}$ & $26.7(\mid 8.7 I)^{b}$ & $27.2(18.58)^{b}$ & $34.2(19.87)^{b}$ & $30.7(20.7 \mathrm{I})^{\mathrm{b}}$ \\
\hline Pain subscale ${ }^{c}$ & $11.0(3.11)$ & $6.3(3.93)^{\mathrm{b}}$ & $5.1(3.86)^{b}$ & $5.2(3.83)^{\mathrm{b}}$ & $6.7(4.25)^{\mathrm{b}}$ & $5.9(4.40)^{b}$ \\
\hline Stiffness subscale ${ }^{d}$ & $4.4(1.63)$ & $2.5(1.74)^{b}$ & $2.0(I .7 I)^{b}$ & $2.0(1.73)^{b}$ & $2.7(1.82)^{b}$ & $2.3(1.89)^{b}$ \\
\hline Physical function subscale ${ }^{e}$ & $38.2(11.06)$ & $23.3(13.84)^{\mathrm{b}}$ & $19.7(13.64)^{\mathrm{b}}$ & $20.1(13.55)^{b}$ & $24.8(14.48)^{\mathrm{b}}$ & $22.4(14.96)^{b}$ \\
\hline
\end{tabular}

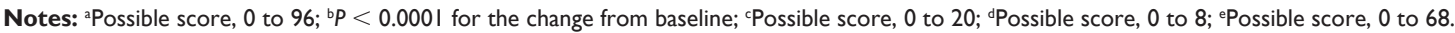

Abbreviations: SD, standard deviation; WOMAC, Western Ontario and McMaster Universities; LOCF, last observation carried forward.

Table A5 Mean (SD) EQ-5D health status index score at baseline and at Weeks 6 and 12 using observed-case analysis (with and without the Week 9-12 data for the Substudy A population) and using the LOCF (without the Week 9-12 data for the Substudy A population) - main analysis population

\begin{tabular}{|c|c|c|c|c|c|c|}
\hline & \multirow{3}{*}{$\begin{array}{l}\text { Baseline } \\
(n=195)\end{array}$} & \multicolumn{3}{|c|}{ Observed-case analysis } & \multicolumn{2}{|l|}{ LOCF } \\
\hline & & \multirow{2}{*}{$\begin{array}{l}\text { Week } 6 \\
(n=I 59)\end{array}$} & \multicolumn{2}{|l|}{ Week I2 } & \multirow{2}{*}{$\begin{array}{l}\text { Week } 6 \\
(n=185)\end{array}$} & \multirow{2}{*}{$\begin{array}{l}\text { Week I2 } \\
\text { Without } \\
\text { Substudy A } \\
(n=164)\end{array}$} \\
\hline & & & $\begin{array}{l}\text { Without } \\
\text { Substudy A } \\
(n=125)\end{array}$ & $\begin{array}{l}\text { With } \\
\text { Substudy A } \\
(n=144)\end{array}$ & & \\
\hline $\begin{array}{l}\text { EQ-5D health } \\
\text { status index score }\end{array}$ & $0.4(0.30)$ & $0.7(0.20)^{\mathrm{a}}$ & $0.7(0.25)^{\mathrm{a}}$ & $0.7(0.23)^{\mathrm{a}}$ & $0.6(0.23)^{a}$ & $0.6(0.28)^{\mathrm{a}}$ \\
\hline
\end{tabular}

Note: ${ }^{a}<0.000$ I for the change from baseline.

Abbreviations: SD, standard deviation; EQ-5D, EuroQol-5 Dimension; LOCF, last observation carried forward. 
Table A6 Mean (SD) SF-36 scores at baseline and at Weeks 6 and 12 using observed-case analysis (with and without the Week 9-12 data for the Substudy A population) and using the LOCF (without the Week 9-12 data for the Substudy A population) - main analysis population

\begin{tabular}{|c|c|c|c|c|c|c|}
\hline \multirow{3}{*}{$\begin{array}{l}\text { Subscale or } \\
\text { summary }\end{array}$} & \multirow{3}{*}{$\begin{array}{l}\text { Baseline } \\
(n=195)\end{array}$} & \multicolumn{3}{|c|}{ Observed-case analysis } & \multicolumn{2}{|l|}{ LOCF } \\
\hline & & \multirow{2}{*}{$\begin{array}{l}\text { Week } 6 \\
(n=159)\end{array}$} & \multicolumn{2}{|l|}{ Week I2 } & \multirow{2}{*}{$\begin{array}{l}\text { Week } 6 \\
(n=185)\end{array}$} & \multirow{2}{*}{$\begin{array}{l}\text { Week I2 } \\
\text { Without } \\
\text { Substudy A } \\
(\mathrm{n}=164)\end{array}$} \\
\hline & & & $\begin{array}{l}\text { Without } \\
\text { Substudy A } \\
(n=125)\end{array}$ & $\begin{array}{l}\text { With } \\
\text { Substudy A } \\
(n=144)\end{array}$ & & \\
\hline Role-physical & $33.5(41.70)$ & $54.2(43.59)^{\mathrm{a}}$ & $65.0(4 I .88)^{\mathrm{a}}$ & $61.8(42.63)^{\mathrm{a}}$ & $53.1(43.70)^{\mathrm{a}}$ & $57.9(43.85)^{\mathrm{a}}$ \\
\hline Physical functioning ${ }^{\mathrm{b}}$ & $30.4(19.36)$ & $47.6(23.52)^{\mathrm{a}}$ & $53.3(25.56)^{\mathrm{a}}$ & $52.7(25.47)^{\mathrm{a}}$ & $45.4(24.78)^{\mathrm{a}}$ & $48.5(26.99)^{\mathrm{a}}$ \\
\hline Bodily pain & $32.5(16.87)$ & $54.0(20.44)^{\mathrm{a}}$ & $62.4(21.97)^{\mathrm{a}}$ & $61.0(21.23)^{\mathrm{a}}$ & $51.7(21.59)^{\mathrm{a}}$ & $56.4(24.43)^{\mathrm{a}}$ \\
\hline General health ${ }^{\mathrm{a}}$ & $46.3(16.55)$ & $55.8(18.77)^{\mathrm{a}}$ & $60.3(20.04)^{\mathrm{a}}$ & $58.6(19.78)^{\mathrm{a}}$ & $53.9(19.01)^{\mathrm{a}}$ & $55.9(20.97)^{\mathrm{a}}$ \\
\hline Vitality & $46.8(17.39)$ & $56.1(19.70)^{\mathrm{a}}$ & $60.0(21.85)^{\mathrm{a}}$ & $58.5(21.92)^{\mathrm{a}}$ & $55.1(19.27)^{\mathrm{a}}$ & $56.9(21.32)^{\mathrm{a}}$ \\
\hline Social functioning & $66.1(25.63)$ & $76.5(23.88)^{a}$ & $82.7(21.58)^{\mathrm{a}}$ & $81.9(21.97)^{\mathrm{a}}$ & $75.5(25.08)^{a}$ & $78.3(26.08)^{\mathrm{a}}$ \\
\hline Role-emotional & $69.2(41.44)$ & $82.2(35.73)^{\mathrm{a}}$ & $81.1(36.01)^{a}$ & $81.9(35.01)^{\mathrm{a}}$ & $80.7(36.54)^{\mathrm{a}}$ & $78.5(37.6 \mathrm{I})^{\mathrm{a}}$ \\
\hline Mental health & $63.1(19.95)$ & $72.1(17.70)^{\mathrm{a}}$ & $75.0(20.20)^{\mathrm{a}}$ & $73.8(20.35)^{\mathrm{a}}$ & $70.5(18.14)^{\mathrm{a}}$ & $72.0(20.5 \mathrm{I})^{\mathrm{a}}$ \\
\hline Physical component & $28 . I(8.5 I)$ & $35.7(10.20)^{\mathrm{a}}$ & $39.3(10.58)^{\mathrm{a}}$ & $38.5(10.56)^{a}$ & $34.9(10.35)^{\mathrm{a}}$ & $36.9(11.24)^{\mathrm{a}}$ \\
\hline Mental component & $50.7(\mathrm{II} .46)$ & $53.7(10.13)^{\mathrm{a}}$ & $54.1(10.45)^{\mathrm{a}}$ & $53.9(10.56)^{\mathrm{a}}$ & $53.2(|0.3|)^{\mathrm{a}}$ & $53.1(11.02)^{\mathrm{a}}$ \\
\hline
\end{tabular}

Notes: a $P<0.05$ for the change from baseline; bbaseline, $n=194$; Observed-case analysis: Week 6, $n=159$; Week 12, without Substudy A, $n=125$; Week 12, with Substudy A, $n=144$; LOCF: Week 6, $n=184$; Week 12, $n=163$.

Abbreviations: SD, standard deviation; SF-36, Short Form-36; LOCF, last observation carried forward.

Table A7 Mean (SD) HADS Anxiety and Depression Subscale scores at baseline and at Weeks 6 and 12 using observed-case analysis (with and without the Week 9-12 data for the Substudy A population) and using the LOCF (without the Week 9-12 data for the Substudy A population) - main analysis population

\begin{tabular}{|c|c|c|c|c|c|c|}
\hline \multirow[t]{3}{*}{ Subscale } & \multirow{3}{*}{$\begin{array}{l}\text { Baseline } \\
(n=192)\end{array}$} & \multicolumn{3}{|c|}{ Observed-case analysis } & \multicolumn{2}{|l|}{ LOCF } \\
\hline & & \multirow{2}{*}{$\begin{array}{l}\text { Week } 6 \\
(n=I 58)\end{array}$} & \multicolumn{2}{|l|}{ Week I2 } & \multirow{2}{*}{$\begin{array}{l}\text { Week } 6 \\
(n=184)\end{array}$} & \multirow{2}{*}{$\begin{array}{l}\text { Week I2 } \\
\text { Without } \\
\text { Substudy A } \\
(\mathrm{n}=163)\end{array}$} \\
\hline & & & $\begin{array}{l}\text { Without } \\
\text { Substudy A } \\
(n=124)\end{array}$ & $\begin{array}{l}\text { With } \\
\text { Substudy A } \\
(n=I 43)\end{array}$ & & \\
\hline Anxiety & $6.7(4.14)$ & $5.2(4.18)^{\mathrm{a}}$ & $4.2(4.26)^{\mathrm{a}}$ & $4.4(4.35)^{\mathrm{a}}$ & $5.5(4.17)^{\mathrm{a}}$ & $5.0(4.48)^{\mathrm{a}}$ \\
\hline Depression & $7.0(3.73)$ & $5.5(3.86)^{\mathrm{a}}$ & $4.9(4.35)^{\mathrm{a}}$ & $5.0(4.23)^{\mathrm{a}}$ & $5.8(3.90)^{\mathrm{a}}$ & $5.4(4.29)^{\mathrm{a}}$ \\
\hline
\end{tabular}

Note: a $P<0.000$ I for the change from baseline.

Abbreviations: SD, standard deviation; HADS, Hospital Anxiety and Depression Scale; LOCF, last observation carried forward.

\section{Publish your work in this journal}

The Journal of Pain Research is an international, peer-reviewed, open access, online journal that welcomes laboratory and clinical findings in the field of pain research and the prevention and management of pain. Original research, reviews, symposium reports, hypothesis formation and commentaries are all considered for publication.

\section{Dovepress}

The manuscript management system is completely online and includes a very quick and fair peer-review system, which is all easy to use. Visit http://www.dovepress.com/testimonials.php to read real quotes from published authors. 